\title{
Hydrothermal Treatment of Vegetable Oils and Fats Aiming at Yielding Hydrocarbons: A Review
}

\author{
Carolina Zanon Costa, Eduardo Falabella Sousa-Aguiar, Maria Antonieta Peixoto Gimenes Couto \\ and José Faustino Souza de Carvalho Filho *
}

Escola de Química, Universidade federal do Rio de janeiro, Rio de Janeiro 21941-909, Brazil; zanoncarol@gmail.com (C.Z.C.); efalabella@eq.ufrj.br (E.F.S.-A.); gimenes@eq.ufrj.br (M.A.P.G.C.)

* Correspondence: faustinocarvalho@gmail.com; Tel.: +55-21-971808257

Received: 7 July 2020; Accepted: 17 July 2020; Published: 26 July 2020

\begin{abstract}
According to the International Air Transport Agency (IATA), the aviation industry causes $2 \%$ of GHG emissions. As a result, goals such as improving aircraft efficiency by $1.5 \%$ per year and achieving carbon-neutral growth by 2020 were established. In this circumstance, fuels produced from biomass seem to be a promising route. There are many routes available to convert biomass into renewable fuels such as pyrolysis, hydroprocessing, transesterification, hydrothermal processes, and steam reforming. In this study, one reports a review of hydrothermal technologies. This review reports recent information about hydrothermal processes using water in sub- and supercritical states. This article introduces some concepts of the hydrothermal processes, advantages, and different types of feedstock adopted. The parameters which have an influence on hydrothermal processes such as temperature, pressure, particle size, catalyst, biomass/water ratio, and reaction time are illuminated. Water characteristics in sub- and supercritical conditions are discussed as a highly reactive medium to increase the affinity for the extraction of value-added compounds. Additionally, this review splits and details the reaction schemes that take place under hydrothermal conditions. Finally, it introduces recent research and development (R\&D) trends in the hydrothermal process of fatty acids and triglycerides.
\end{abstract}

Keywords: hydrothermal processing; subcritical water; supercritical water; in situ hydrogen; decarboxylation; renewable hydrocarbons

\section{Introduction}

Biofuels are becoming fundamental fuels nowadays, due to environmental regulations. Several techniques may be used to produce biofuels. Among the main biofuel production techniques, there are pyrolysis, catalytic hydroprocessing, transesterification, catalytic cracking, and gasification combined and processed with the Fischer-Tropsch synthesis (Figure 1) [1]. In fact, techniques such as catalytic hydroprocessing and pyrolysis have a high energy expenditure. Moreover, as far as hydroprocessing is concerned, the presence of hydrogen as a reactant is necessary. However, hydrogen is currently produced via steam reforming of either naphtha or natural gas, with the formation of syngas $\left(\mathrm{CO}+\mathrm{H}_{2}\right)$, and it is a process in which $\mathrm{CO}$ is a co-product. To eliminate $\mathrm{CO}, \mathrm{CO}$ reacts with excess steam, via the water-gas shift reaction (WGS), and gas is obtained containing essentially $\mathrm{H}_{2}$ and $\mathrm{CO}_{2}$. Furthermore, in some cases, biomass pretreatment has to be carried out, thereby increasing the CAPEX of the process. 


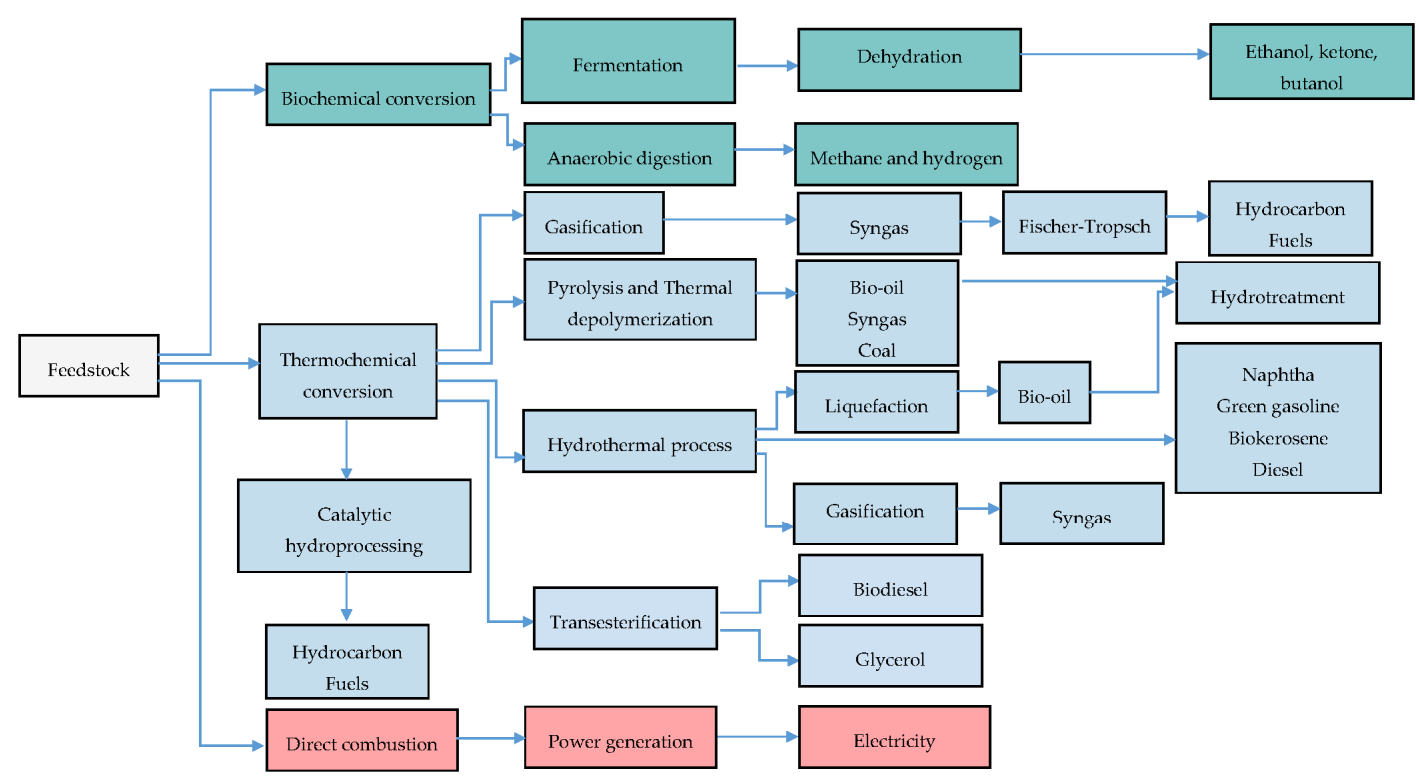

Figure 1. Technological processes for the production of biofuels [2-4].

Hence, much research has been performed aiming at developing a new route to generate biofuels. This route ought to avoid biomass pretreatment and reduce energy consumption. Hydrothermal technologies seem to be quite promising to meet such demands.

Hydrothermal technology is an example of successful development for the production of biofuel that could replace catalytic hydroprocessing. The hydrothermal technology offers numerous advantages over other green fuel production methods: high energy and high efficiency in the separation of products; facility to use simultaneously different raw materials; and the possibility of processing wet raw materials, the production of drop-in fuels, and the combination with other techniques that produce biofuels [5].

According to what has been exposed, the objective of this manuscript is to submit a review of hydrothermal technologies. Furthermore, a complete literature review is presented with studies related to the conversion of vegetable oils and fatty acids to renewable hydrocarbons. Until now, no review has been published with a focus on hydrothermal studies for vegetable oils and fatty acids displaying main parameters and experimental results. This article collects all information about the hydrothermal process of triglycerides and fatty acids, thereby helping future research in this subject. Furthermore, it must be borne in mind that, although other reviews have been published regarding the aforementioned topic, they do not present the level of detail required to support future research in the area.

There are seven sections in this manuscript. In Section 1, hydrothermal technology is introduced. In Section 2, we introduce the context of the hydrothermal process; the advantages present in it over the other methods such as catalytic hydroprocessing, pyrolysis, and Fischer-Tropsch; and the two regions where hydrothermal technology occurs-subcritical and supercritical. We discuss the regions in the subcritical and supercritical states that occur in hydrothermal technology and that are determined by the severity (temperature and pressure) of the conditions employed during their process. Finally, we elucidate the characteristics and the importance of water under sub- and supercritical conditions. In Section 3, we present the reactions that occur under sub- and supercritical states. In Section 4, we introduce and explain important parameters in the hydrothermal process. In Section 5, we comment on the main feedstock used in hydrothermal technology. All discussions about hydrothermal technology in Sections 1-5 were interpreted while taking into account previously published literature reviews. Finally, a complete literature review is presented, along with an assessment of articles regarding the transformation of vegetable oils and fatty acids to renewable hydrocarbons. Moreover, general trends and challenges for hydrothermal experiments using vegetable oils and fatty acids are discussed in Section 6. 


\section{Hydrothermal Technologies}

Hydrothermal technologies are generally defined as a process that provides chemical and physical transformations through the application of high temperature (473-874 K) and high pressure (5-40 MPa) to water near its supercritical state. The main objective of the hydrothermal process is to convert different types of feedstock into liquid renewable fuels, fuel gas, or other valuable chemical products. Furthermore, it offers innumerable advantages over other methods of producing biofuels. In this context, Table 1 presents the advantages of the hydrothermal process $[5,6]$.

Table 1. Advantages and disadvantages of the hydrothermal process.

\begin{tabular}{lc}
\hline \multicolumn{1}{c}{ Advantages } & Disadvantages \\
\hline High energy and efficiency of separation & Corrosion \\
It can use different raw materials at the same time & Coke and tar formation \\
Production of drop in fuels & Blockage and obstruction of the reactor \\
Unnecessary deployment of microorganisms and enzymes & $\begin{array}{c}\text { Difficulty in recycling and regenerating the catalysts } \\
\text { Combination with other techniques }\end{array}$ \\
\hline
\end{tabular}

Another advantage of the hydrothermal process is the presence of efficient heat integration. If the reactions occur at temperatures above $250^{\circ} \mathrm{C}$, an aqueous phase is produced. The residual carbon compounds present inside this aqueous phase can be used for the production of biogas. For this, however, the aqueous phase must undergo anaerobic digestion. This biogas can later be directed to the generation of heat and energy, which reduces the energy expenditure of the technology and leads to the concept of integrated biorefinery [6].

The hydrothermal processing has two states: the subcritical and the supercritical states. These regions are defined regarding the water critical point $(\mathrm{Tc}=646 \mathrm{~K}, \mathrm{pc}=22.1 \mathrm{MPa})$. When the hydrothermal technology occurs below $646 \mathrm{~K}$ and $22.1 \mathrm{MPa}$, the reaction occurs in the subcritical region. When the temperature and pressure are higher than $646 \mathrm{~K}$ and $22.1 \mathrm{MPa}$, the process happens in the supercritical region. Fundamentally, the feedstock becomes soluble into the water at $473 \mathrm{~K}$, and then above $473 \mathrm{~K}$, the hydrolysis of the raw material occurs. Afterward, according to the interested product, the process proceeds in the direction of liquefaction or gasification [7].

The hydrothermal process performed close and over the water critical point $(647 \mathrm{~K}, 22 \mathrm{MPa})$ is attractive for the transformation of biomass because of three main explanations [5]:

- It allows the use of feedstock with high humidity. There is no necessity to have a pretreatment for the thermal separation of water, so there is no loss of the biomass energy content.

- There is flexibility of chemical substances. For example, the lignocellulosic feedstock contains fatty acids or protein that can be converted into different products, such as methane, hydrogen, crude oil, renewable diesel, and biogasoline, among others.

- It allows for improvements in reaction rates and efficient separations. Operation under supercritical or hydrothermal conditions reduces and eliminates resistance to mass transfer. In addition, it improves selectivity for more desirable energy products. The facility to separate products and by-product streams is related to significant modifications in the physical properties of water that happen with changes in the parameters of temperature and pressure, thereby reducing the necessity of the consumption of energy to purify products.

Although the techniques in the sub/supercritical water environment have wide applicability and are mostly advantageous, there are still bottlenecks in this methodology that require process optimization. Part of this is because of the necessity of elevated pressures for the processing, which requires reactor and separator designs with high capital investments, principally for full-scale plants. Besides, there are still several other critical topics hindering commercialization that have to be resolved so that the technologies can be piloted and ultimately scaled up. These include corrosion in the subcritical water environment and can be localized, general, intercrystalline, and stress. Acidic and oxidizing environments can cause corrosion, and this may be even more severe under subcritical medium than 
under supercritical state, because of the polarity of the water molecule. Because of this, the most used material for subcritical reactions is a metal alloy of nickel and titanium (even with limited mechanical strength). Other disadvantages that need resolution are the formation of coke and oil tar, the clogging of the reactor, and its obstruction caused by the precipitation of organic salts combined with coke $[8,9]$.

\subsection{Hydrothermal Regions in Sub- and Supercritical Water}

Several distinct regions divide the hydrothermal process at the subcritical and supercritical states, depending on the severity of the conditions employed during its processing. When subjected to an environment of low severity (323-393 K), rapid hydrolysis is achieved without profound changes in molecular structure. This process is commonly used in the treatment of lignocellulose for the production of bioethanol $[5,7]$.

When the raw material is treated from 393 to $523 \mathrm{~K}$ for a long period, the process corresponds to hydrothermal carbonization with the production of a carbon/coke rich in carbon, and with properties similar to low-class coal [10].

When the hydrothermal reactions occur at a temperature close to the supercritical water (523-647 K and $<220$ bar), the water becomes highly compressible and the processed raw material undergoes several chemical transformations producing a liquid substance with chemical characteristics completely diverse from the initial ones [7]. By increasing the temperature of subcritical conditions to a value considered supercritical at pressures above the critical point, it is possible to control the hydrolysis rate, phase change, and solubility of the components and convert biomass in liquid or gaseous fuels [5]. In addition, the changeover to the hydrothermal gasification can also be carried out by modifying the temperature. It will take advantage of the lower quantity of organic carbon found in the aqueous phase, which leads to high carbon efficiency [10].

Finally, when carrying out the process at temperatures above $647 \mathrm{~K}$ (in supercritical water), gasification reactions dominate the process. This methodology is hydrothermal gasification, resulting in the production of synthetic fuel gas [10]. All hydrothermal regions in the sub- and supercritical states are depicted in Figure 2.

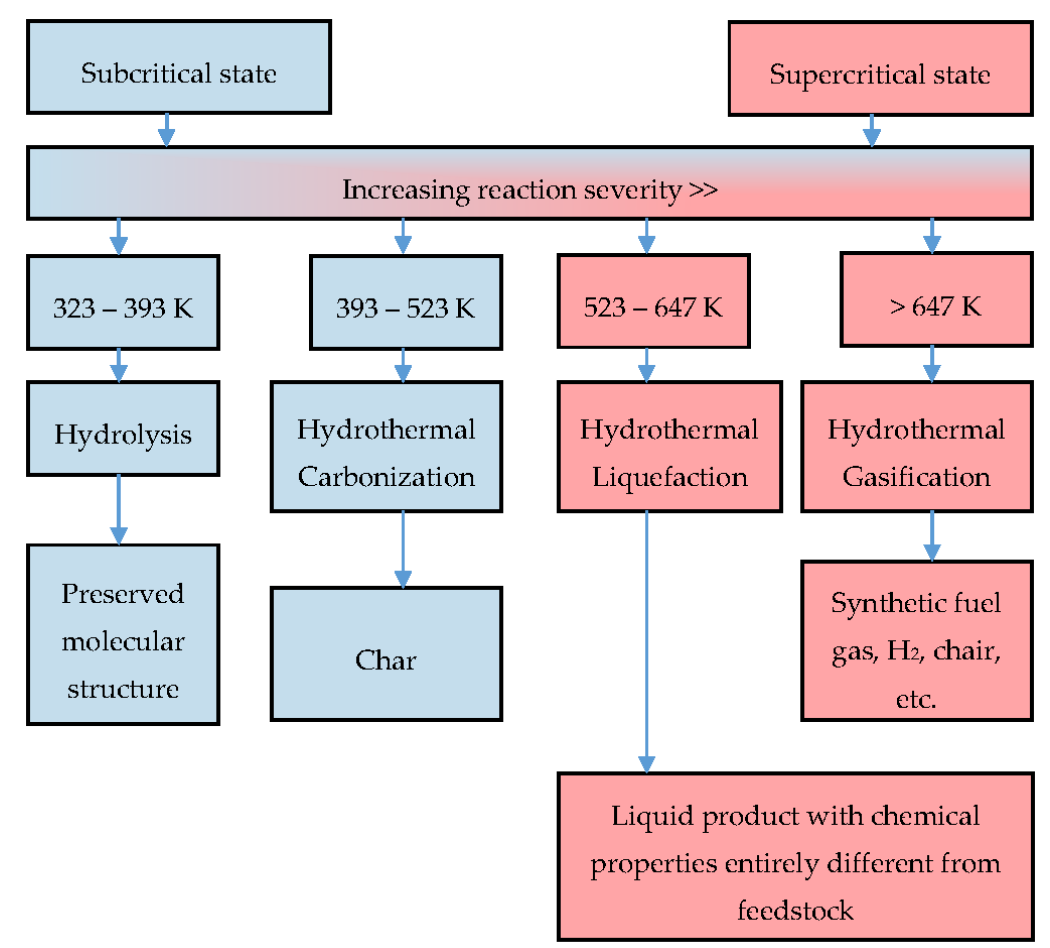

Figure 2. Regions at the subcritical and supercritical states in hydrothermal process. 


\subsection{Water in Sub-and Supercritical States}

The main reactive medium of hydrothermal technologies is water. At $298 \mathrm{~K}$, water is inert to most organic reactions. When the temperature increases and approaches the region near $646 \mathrm{~K}$ and $22.1 \mathrm{MPa}$, its chemical characteristics such as density, ionic product, viscosity, and dielectric constant change rapidly (Table 2). This allows the water to act both as a catalyst and as a reactant. As a result, for most homogeneous organic reactions in the supercritical state, the water becomes an excellent solvent due to the elevated miscibility and absence of any phase limits. As a matter of fact, in regions near the supercritical point, water reacts as a solvent with a "nonpolar" characteristic, although it continues with a dipolar moment of $1.85 \mathrm{D}$ (characteristic of polar molecules) [5,8].

Table 2. Characteristics of water in different temperature ranges.

\begin{tabular}{cccc}
\hline Parameters & Water & Subcritical Water & Supercritical Water \\
\hline Temperature (K) & 298 & 523 & 673 \\
Pressure (MPa) & 0.1 & 5 & 25 \\
Density (g/cm ${ }^{3}$ ) & 0.997 & 0.80 & 0.17 \\
Viscosity (m Pa s) & 0.89 & 0.11 & 0.03 \\
Dielectric constant & 78.5 & 27.1 & 5.9 \\
Heat capacity (KJ/Kg K) & 4.22 & 4.86 & 13 \\
Thermal conductivity (mW/mK) & 608 & 620 & 160 \\
\hline
\end{tabular}

In addition, water will have intermediate comportment of a gas and a liquid and will act through the two phases via a free radical mechanism. Initially, free radicals are induced, so that their reactions occur. Thus, the formation of hydronium ions at high temperature and pressure is responsible for the generation of alkyl radicals and the heterocyclic compounds may undergo ring-opening. Moreover, it will be responsible for the decarboxylation, decarbonylation, and hydrolysis reactions of biomass $[5,6]$.

Another aspect that influences the performance of water as a nonpolar compound is the value of dielectric constant. At $298 \mathrm{~K}$, water has a dielectric constant of about $80 \mathrm{~F} / \mathrm{m}$. However, as the water gets closer to the critical point $(646 \mathrm{~K})$, the dielectric constant decreases, reaching $5 \mathrm{~F} / \mathrm{m}$. Such behavior is similar to that of a nonpolar solvent, which makes it a suitable medium for the solvation of the organic molecules. Hence, it will provide higher reaction rates as a result of improved nucleophilic eliminations and substitutions and then hydrolysis reactions. Consequently, it is possible to observe that there is an increase in its miscibility with the organic compounds, providing reactions in a single phase. This is generally due to the decrease of the hydrogen bonds of the water molecule with increasing temperature $[6,8,11]$. Table 3 shows the chemical characteristics of water in a subcritical and supercritical state and the properties of some nonpolar solvents.

Table 3. Exemplification of the properties of nonpolar solvents and water.

\begin{tabular}{|c|c|c|c|c|c|c|c|}
\hline Parameters & Sub ${ }^{a}$ & Sup $b$ & $\operatorname{DCM}^{\mathrm{c}}$ & THF $^{d}$ & $\mathrm{CF}^{\mathrm{e}}$ & $\operatorname{Hex}^{f}$ & $\mathrm{Cy}$ \\
\hline Density $\left(\mathrm{g} \mathrm{cm}^{-3}\right)$ & 0.80 & 0.17 & 1.33 & 0.89 & 1.49 & 0.66 & 0.77 \\
\hline Viscosity (m Pa s) & 0.11 & 0.3 & 0.45 & 0.46 & 0.55 & 1.89 & 0.83 \\
\hline Dielectric constant (at $293 \mathrm{~K}$ ) & 27.1 & 5.9 & 8.93 & 7.58 & 4.81 & 1.89 & 2.02 \\
\hline
\end{tabular}

${ }^{\mathrm{a}}$ Subcritical water; ${ }^{\mathrm{b}}$ supercritical water; ${ }^{\mathrm{c}}$ dichloromethane; ${ }^{\mathrm{d}}$ tetrahydrofuran; ${ }^{\mathrm{e}}$ chloroform; ${ }^{\mathrm{f}}$ hexane; ${ }^{\mathrm{g}}$ cyclohexane.

The same occurs with the viscosity of the water. The increase in temperature tends to decrease it, resulting in a higher coefficient of diffusion and mass transfer. This water-gas behavior (when performed above the critical point), combined with the molecular rearrangement of the water, facilitates the dissolution of the non-polar chemicals and ionic bonding substances, which consequently decreases the mass transfer restriction $[6,8,11]$.

Another modification present in water is the decrease of its ionic product, because of dissociation and the generation of ions (hydroxide and hydronium). As an example, at $523 \mathrm{~K}$, the ionic product of 
water reduces from 14 to 11 [7]. This occurs because supercritical water has high concentrations of hydronium ions and hydroxyls. Consequently, it enables its action as an acidic or basic catalyst in the reactions. An example is organic chemicals that cannot react in water without the presence of a strong catalyst, either acid or basic, but readily react under hydrothermal conditions of supercritical water [11].

Another important issue is the variation in the heat capacity of water from 4.2 to $13 \mathrm{~kJ} \mathrm{~kg}^{-1} \mathrm{~K}^{-1}$ when temperature increases from 298 to $673 \mathrm{~K}$. This increase improves heat transport in the reaction by reducing the required energy to maintain the reaction temperature and results in an important economic advantage [11].

After discussing all the changes that occur with water in the supercritical region, it is important to present the performance of water. Initially, the free radicals are induced. Thus, the formation of the hydronium ions is responsible for the generation of the alkyl radicals, and heterocyclic substances may undergo the ring-opening. Furthermore, it will be responsible for the decarboxylation, decarbonylation, and hydrolysis reactions of the biomasses $[5,6]$.

All the physicochemical changes of the water will have important results on the product formed by the hydrothermal process. Thus, its function in hydrothermal technology cannot be undervalued, since the simple variation of the temperature, pressure and residence time may bring about a significant difference in the products yielded $[5,7]$.

\section{Reactions in the Hydrothermal Process}

At present, the discussions regarding the main reactions which may take place in hydrothermal technologies are largely qualitative. This is because the processed feedstock is a complex combination of several substances such as carbohydrates, lignin, proteins, and lipids. Therefore, the reactions of the raw materials present in subcritical and supercritical water will also be complex. Besides, there is a multitude of possible intermediate reactions, and this makes impossible the identification of the main reactions that are carried out in the hydrothermal medium. These multiple reactions occur because of the coexistence of the liquid and gaseous phases of the water. It has already been proven, however, that vegetable oils will first undergo hydrolysis reactions to generate fatty acids, which will then undergo dehydration, dehydrogenation, deoxygenation reactions (hydrodeoxygenation, decarbonylation, and decarboxylation reactions) [12]. Moreover, both short- and long-chain saturated fatty acids may suffer other reactions-for example, methanation $\left(\mathrm{CH}_{4}\right.$ production), steam reforming $\left(\mathrm{H}_{2}, \mathrm{CO}\right.$ and $\mathrm{CO}_{2}$ generation), thermal cracking (methane, acetylene, ethylene, ethane and propane generation), and catalytic cracking reaction-to produce light hydrocarbons (depending on the type of catalyst).

The increase in the miscibility between triglycerides and water favors reactions that occur in supercritical water temperature. There is an increase in the acid/base characteristics of the water, and ionic and hydrolysis reactions are favored [5].

The hydrolysis dissociates the triglyceride into fatty acids and glycerol. While the reaction occurs, more free fatty acids are generated, which further increase the solubility of water in the oil phase and the reaction rate. At the same time, the glycerol produced by the hydrolysis of the triglycerides decomposes into methane, $\mathrm{CO} 2$, and can be used for in situ production of hydrogen. Besides, the hydrogen produced accelerates hydrolysis and is used in the hydrogenation, in which the unsaturated fatty acids are hydrogenated into saturated fatty acids (by breaking $\pi$ bonds) $[5,13,14]$.

Then, as aforementioned, saturated fatty acids may undergo dehydration, dehydrogenation, hydrodeoxygenation, decarbonylation, and decarboxylation reactions and this will depend on the catalyst implemented during the hydrothermal reaction. Dehydration removes the oxygen heteroatom with the formation of water; the decarboxylation eliminates oxygen in the form of $\mathrm{CO}_{2}$ and the decarbonylation in the form of $\mathrm{CO}$. These three reactions are important since they provide the removal of oxygen from the fatty acid and the formation of long-chain hydrocarbons. Furthermore, they also 
raise the carbon/hydrogen ratio, which normally results in more attractive fuels $[5,8,12]$. Scheme 1 shows the reaction pathways of the hydrothermal process from a glyceride.

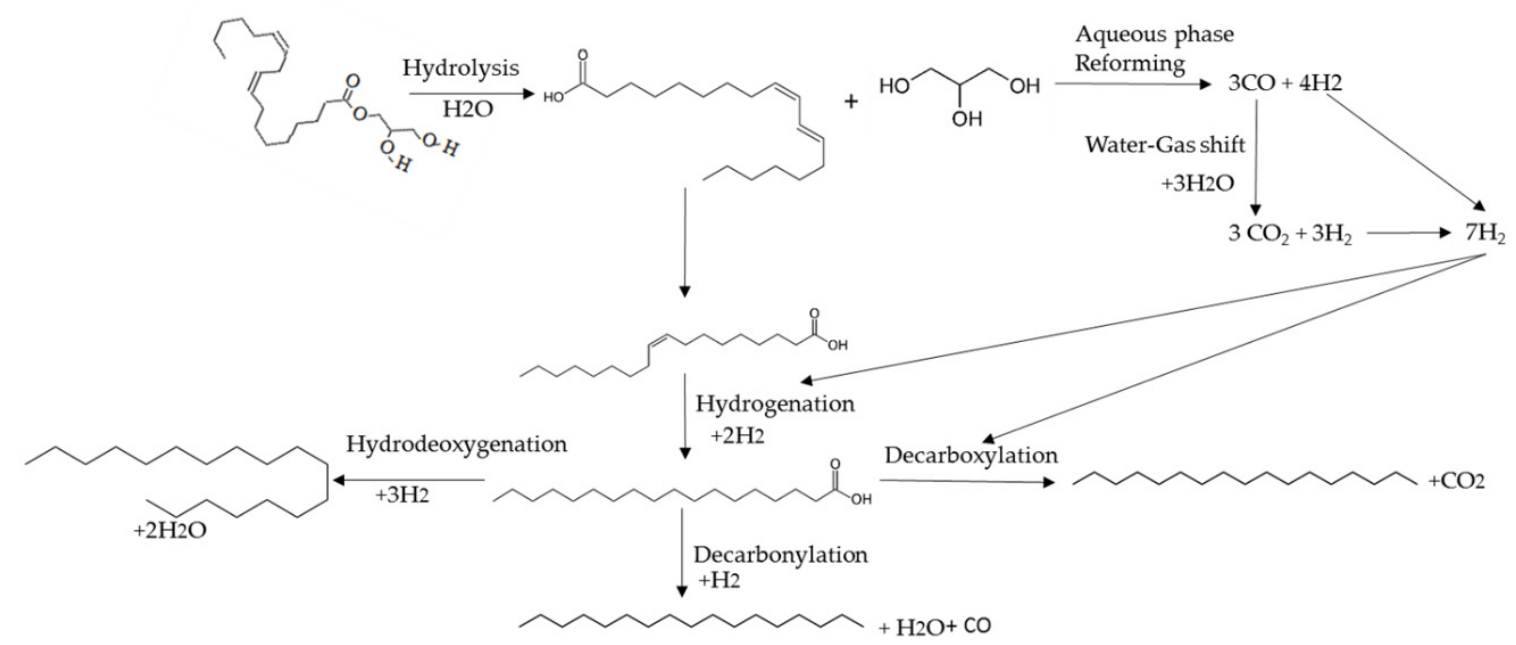

Scheme 1. Reaction pathways for catalytic hydrothermal conversion of monoglyceride to n-alkane hydrocarbons.

Robin, Jones, and Ross [15] proposed an alternative reaction scheme, which is being demonstrated in Scheme 2. Firstly, at a temperature inferior to $523 \mathrm{~K}$, the hydrolysis of triglycerides in fatty acids and glycerol happens, and it could occur with the absence of catalyst in the medium. Afterward, there are inter-cyclic reactions of the unsaturated fatty acids, and dimers are produced, such as the "Diels-Alder" intracyclization between octadec-9-enoic and octadeca-9,12-dienoic acids. Finally, it involves the fatty acids are decarboxylated into aldehydes and alkenes. The unconjugated of 10,12-octadecadienoic can also be reduced into the aldehyde Z,Z-10,12-hexadecadienal. The Z,Z-10,12-hexadecadienal can be hydrogenated to generate the Z,Z-10-12-hexadecadienol, to be subsequently dehydrated, forming its corresponding alkene.

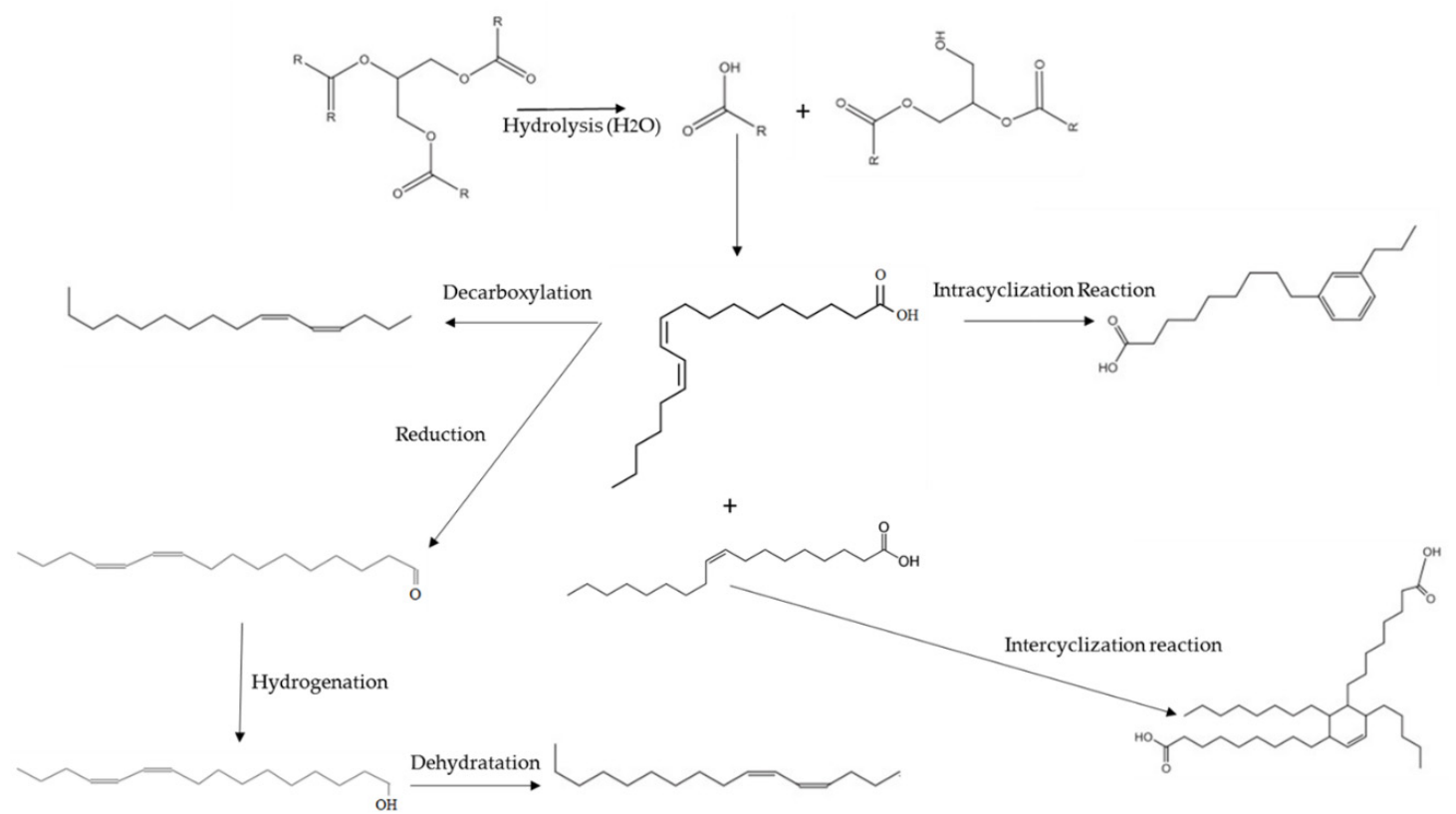

Scheme 2. Proposed reaction pathways through the hydrothermal process of triglyceride [15]. 
A critical analysis of the main reactions that occur in the hydrothermal process justifies the need to continue research on this process. For this, however, it is necessary to use isolated fatty acids instead of vegetable oils or triglycerides. Vegetable oils can be described as a complex mixture of triglycerides. This complexity brings the possibility of innumerable intermediate reactions, in which research becomes observation only and limits innovation in the field.

\section{Important Parameters in the Hydrothermal Process}

In reference to the influential parameters of hydrothermal technologies, conditions such as temperature, pressure, particle size, catalyst, biomass/water ratio and reaction times influence the hydrothermal processes $[6,12,16]$.

Temperature influences the range of the hydrothermal process (fractionation, carbonization, liquefaction, or hydrothermal gasification). Pressure assists to preserve water in the liquid state and thus avoid the high-energy costs of a liquid-vapor system. In the hydrothermal technology close to the supercritical region, the production of a liquid product with chemical characteristics very diverse from the feedstock will occur. In case of the hydrothermal gasification (above $647 \mathrm{~K}$ ), the gasification reactions start to prevail in the process, producing synthetic combustible gas [5], while temperatures between 573 and $623 \mathrm{~K}$ produce higher amounts of the organic phase [6,17].

Reaction time influences the composition of product and conversion efficiency. Under supercritical conditions, the degradation occurs rapidly; thus, shorter residence times are often desirable. This is because, the longer the residence time, the greater the possibility of secondary reactions dominating the hydrothermal process.

The nature of the raw material affects the bio-oil yield and the product that will be produced. Particle size acts on accessibility and heat penetration into the raw material. Because of this, smaller particles favor heat performance and the conversion rate and efficiency of the bio-oil [6].

Catalysts are used to improve the efficiency of the hydrothermal process, mitigating the formation of tar and coal. The choice for homogeneous catalysts is due to advantages such as a reduction in solids production, an increase of yield, improvement in the properties of formed bio-oils, and a reduction of dehydration reactions. Moreover, homogeneous alkali metal catalysts reduce the formation of coal and tar and improving product yield. Furthermore, homogeneous alkali metal catalysts do not present deactivation problems the way heterogeneous catalysts do [5]. However, there is a difficulty in separation/recycling steps, which consequently increases the process cost $[6,8]$.

Heterogeneous catalysts facilitate the purification or recycling step. In addition, their use avoids the need for an extra product purification step. They are generally used in hydrothermal processes in supercritical regions of water, where positive effects are reported. However, they are prone to fouling and subsequent deactivation $[6,8]$.

Even though most hydrothermal studies use homogeneous catalysts in the form of alkaline salts, it is possible to find the use of heterogeneous catalysts as Ni-containing catalysts $[6,13]$. Kumar, Oyedun, and Kumar [6] showed great potential for nanocatalysts involving the use of nickel in the improvement of the yield of bio-oil at low temperatures.

Nowadays, there are preferences for metal catalysts containing Pt, Pd, and Ni. For the catalysts of $\mathrm{Pt} / \mathrm{C}$ and $\mathrm{Pd} / \mathrm{C}$, besides their high cost, the high selectivity to $\mathrm{CO}$ formed by the decarbonylation of carbonic acid and the rapid deactivation due to the formation of coke were verified [18].

In addition, there is the use of solid acid catalysts, e.g., zeolites. Zeolites seem to be more appropriate for generating lighter fractions of hydrocarbon from triglycerides of fatty acids. Currently, ZSM-5 is widely used in the petrochemical industry and petroleum refining due to its acidity, its selectivity, and its meso- and microporous structure. In addition, ZSM- 5 has a high concentration of Lewis acidic sites [19].

For vegetable oils and fatty acids, parameters such as residence time, reaction temperature, and catalysts are seen as important for ensuring efficiency in experimental results. 


\section{Main Feedstocks in the Hydrothermal Process}

In the hydrothermal process, it is possible to use different types of raw material. Each raw material, according to the chosen parameters at the hydrothermal process, will produce different products. The main raw materials currently being used in the hydrothermal process are carbohydrates, lignin, waste, microalgae, and triglycerides or fatty acids (Figure 3) [5-8,11,12].

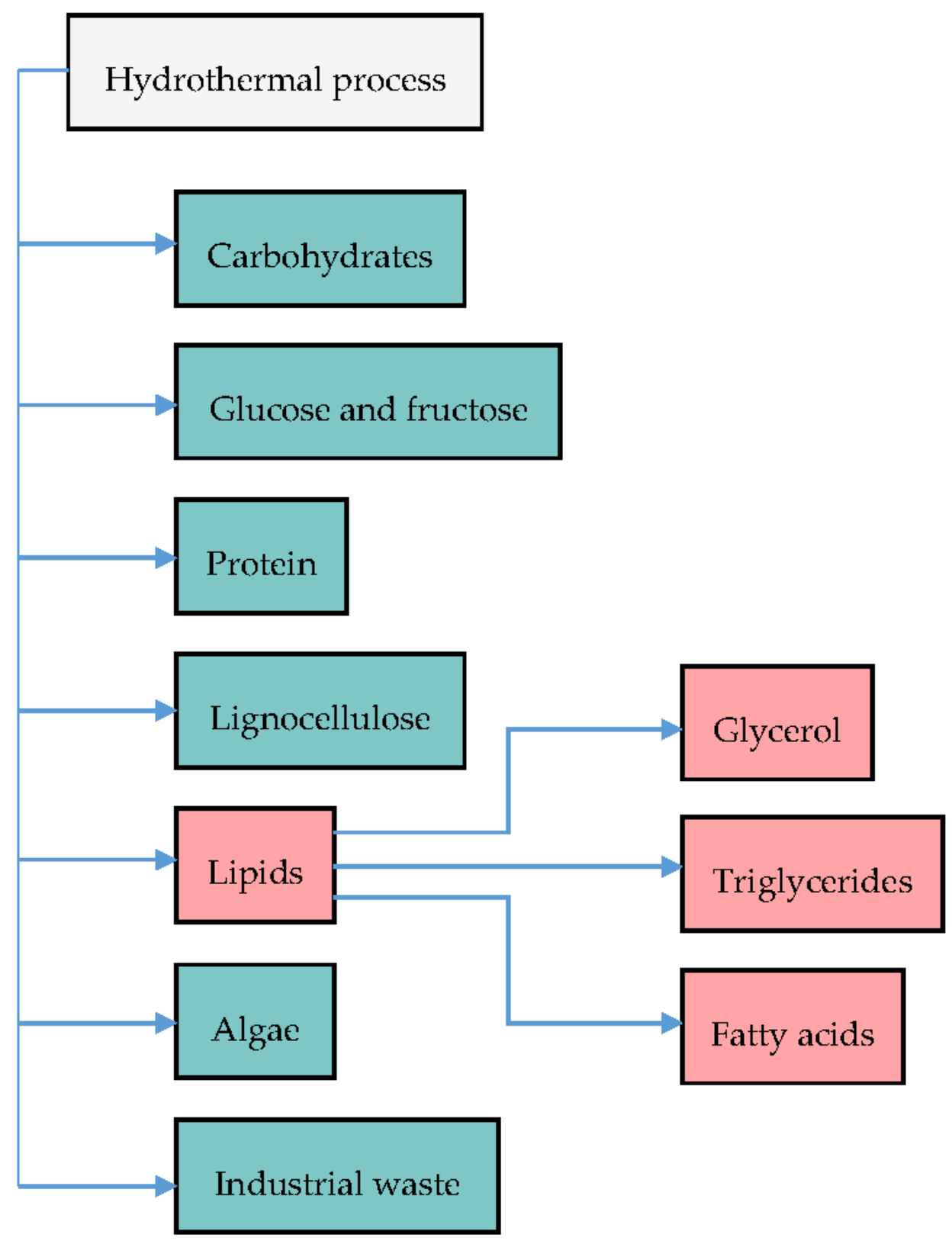

Figure 3. Raw materials used in the hydrothermal process.

Carbohydrates: Carbohydrates are divided into hemicellulose, cellulose, polysaccharides, and starch. When carbohydrates are in the hydrothermal states, they are hydrolyzed rapidly and form glucose and other saccharides. When glucose and fructose are degraded in hydrothermal medium, several substances are obtained, e.g., acetic acid, acetone, acrylic acid, acetaldehyde, arabinose, cellobiose, pyruvaldehyde, 5-Hydroxymethylfurfural (5-HMF), lactic, levulinic, formic, furfural, and glycolic acids, as well as several gaseous products [6,20]. Cellulose is hydrolyzed slower than hemicelluloses and starch. In hydrothermal environments, hemicellulose decomposes to produce 
several monosaccharides, the most predominant being the 5-carbon sugar xylose. During the hydrothermal process in the subcritical state, the cellulose is rapidly solubilized and hydrolyzed, occasioning in the formation of glucose monomers. In addition, cellulose also undergoes hydrothermal degradation, which affects glucose yield. Starches are rapidly hydrolyzed in hydrothermal reactions with no addition of acids or enzymes. However, yields of glucose are lower than methods that use conventional enzymes, because these methods cause further degradation of glucose or decomposition of the starch into oligomers $[5,8,20]$.

Lignocellulose: Cellulose, hemicellulose, and lignin are substances that compose the lignocellulose. The hydrothermal process of lignin generates significant quantities of solid residue, and, consequently, the quantity of lignin in the feedstock should be carefully balanced. Basically, lignin is degraded into various phenols and methoxy phenols, and these substances can also decompose more by hydrolysis of methoxy groups $[8,20]$. Figure 4 shows the hydrothermal process from lignocellulose.

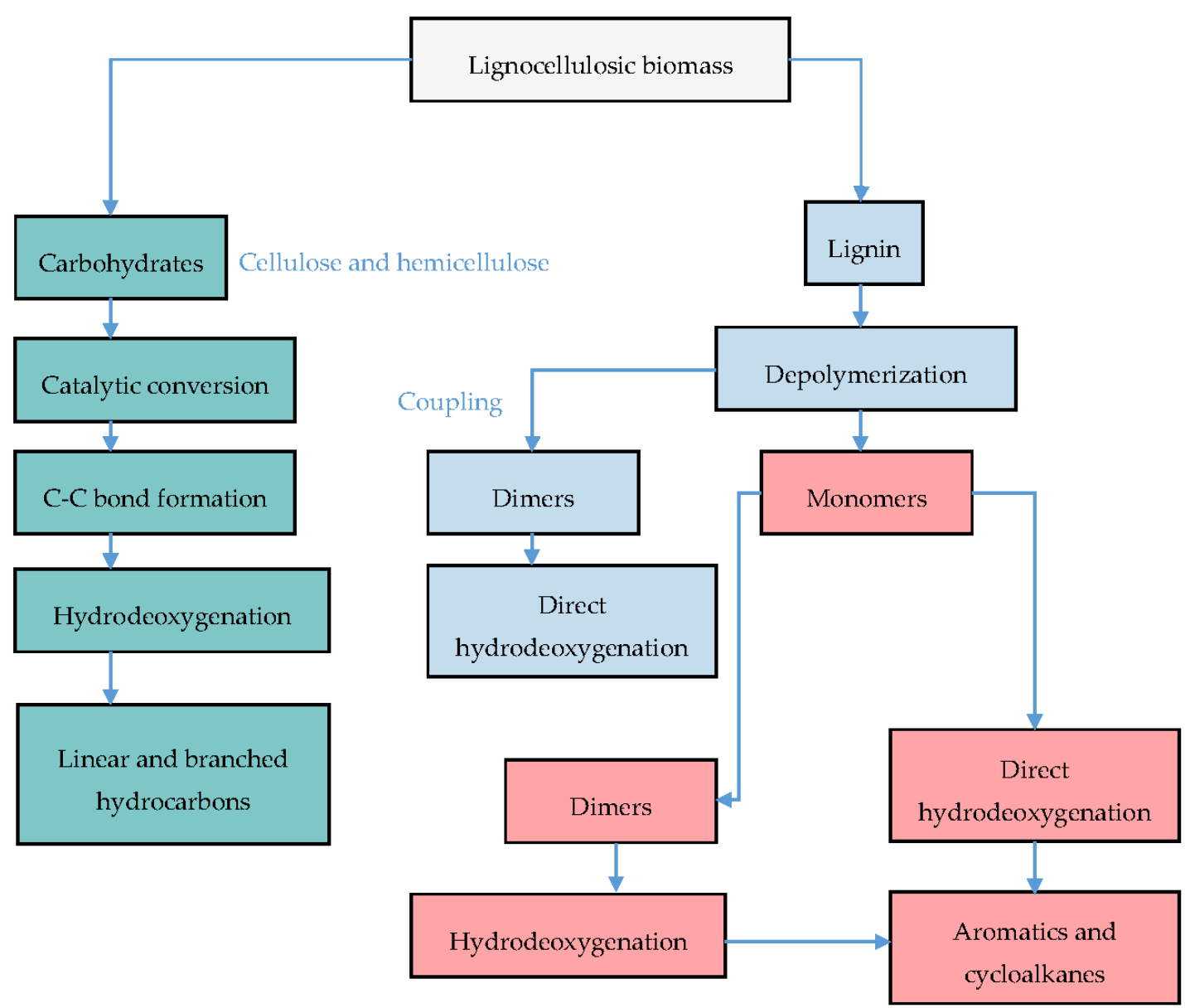

Figure 4. Hydrothermal conversion of lignocellulosic biomass (carbohydrates and lignin) to hydrocarbons, aromatics, and cycloalkanes [8].

Protein: In the hydrothermal process of protein, the peptide bond hydrolyzes rapidly. However, the yields of amino acids attained conventionally are usually higher than yields of them at hydrothermal reactions, since in the hydrothermal medium, there is a successive decomposition of amino acids generated by hydrothermal hydrolysis. Furthermore, the products formed by hydrothermal processes of amino acids are acquired via reactions of decarboxylation and deaminization $[5,8,20]$.

Industrial waste. Some researchers have studied hydrothermal technology from industrial waste as feedstock to produce fuel, as it adds value to waste through the formation of fuel and fertilizer, and it removes the chance of pathogen growth in the food chain. Kipçak et al. [21] studied the production of 
fuel gas at $773 \mathrm{~K}$ with the residue of olive oil. Nanda et al. [9] studied the hydrothermal gasification of aloe peel, banana, coconut, lemon, orange, pineapple, and sugarcane bagasse to produce hydrogen-rich synthesis gas. The highest yield for $\mathrm{H}_{2}$ and fuel gas was with orange peel, at $873 \mathrm{~K}$ and $45 \mathrm{~min}$ time.

Lipids: Under supercritical hydrothermal conditions, the hydrolysis of the triglycerides can easily occur, provided a catalyst is used. This occurs because the phase behavior substantially influences the reactions between lipid and water. When the water is heated from $298 \mathrm{~K}$ to values above $647 \mathrm{~K}$, the solvating characteristics of the water correspond to the organic solvents. This results in weaker hydrogen bonds between the water molecules, permitting greater miscibility between the triglycerides and the water. When the temperature reaches the supercritical state of water, the lipids become completely miscible $[6,8,12]$.

Triglycerides are hydrolyzed to fatty acids and glycerol. As the reaction proceeds and the temperature increases, the generation of fatty acids growth, which increases the water solubility in the oil phase [5]. Posteriorly, free fatty acids react in hydrothermal systems to produce long-chain hydrocarbons. Most of the hydrothermal processes use soybean oil as a raw material to obtain renewable hydrocarbons. However, it is possible to find other documents that applied different raw materials, such as coconut oil, tallow, and fatty acids present in Litsea cubeba and Jatropha oil [5,13,22].

\section{Recent Approaches in the Hydrothermal Process}

\subsection{Review of Experimental Articles}

\subsubsection{Triglycerides}

Investigations on the hydrolysis of triglycerides under subcritical water can be realized to form fatty acids. Studies of thermal stability of fatty acids demonstrated that unsaturated fatty acids are thermally less stable than saturated fatty acids, and fatty acids can behave such as an acid catalyst in the reaction of hydrolysis when they are in a subcritical state of water. In addition, several studies confirmed that the hydrolysis of triglycerides produces isomerized fatty acids via the isomerization reaction of unsaturated fatty acids from cis to trans form. Based on several studies, hydrolysis of lipids under subcritical water should happen below $573 \mathrm{~K}$ (at $20 \mathrm{MPa}$ ) and with residence time inferior to $30 \mathrm{~min}$ to produce a high yield of fatty acids [20]. Holliday, King, and List [23] studied the hydrolysis of soybean, linseed, and coconut oils to fatty acids with $0.7 \mathrm{~g} \mathrm{~mL}^{-1}$ of water, without the presence of a catalyst and with temperatures of 533-553 K. They observed that coconut oil hydrolyzed more quickly (15 $\mathrm{min})$, while linseed oil took longer $(20 \mathrm{~min})$. While concentrations of saturated acids (octanoic, decanoic, dodecanoic, tetradecanoic, hexadecanoic, and octadecanoic acids) and unsaturated acids (octadec-9-enoic and octadeca-9,12-dienoic acids) were stable at temperatures below $573 \mathrm{~K}$, the concentration of octadeca-9,12-dienoic acid was reduced in the same circumstances, through the reactions of isomerization and degradation. In addition, the GC-FAME analysis demonstrated that fatty acids underwent severe degradation, pyrolysis, or polymerization. Finally, they observed that hydrolysis occurred quickly and the conversion of triglycerides to fatty acids was greater than $97 \%$ after 15-20 min at 543-553 K. Alenezi et al. [24] analyzed the thermal hydrolysis of sunflower oil in the subcritical state of water and without a catalyst. They used temperatures ranging between 543 and $623 \mathrm{~K}$, reaction times (up to $30 \mathrm{~min}$ ) at $20 \mathrm{MPa}$, and the ratio of water/sunflower oil was $50 / 50(v / v)$. They noticed that fatty acid can behave like an acid catalyst in the reaction of hydrolysis under subcritical water and yield until $90 \mathrm{wt} \%$ conversion of glycerides (triglycerides, diglycerides, and monoglycerides) to fatty acids without the use of any catalyst. Another article was published by Fujii et al. [25]. They confirmed that a first-order reaction boosts the kinetics of degradation of monolaurin in the aqueous phase and demonstrated a first-order reaction rate that follows an Arrhenius kinetics, with activation energy of $77.5 \mathrm{~kJ} \mathrm{~mol}^{-1}$ and factor frequency range $1.01 \times 10^{5} \mathrm{~s}^{-1}$ at 483 , 503,523 , and $543 \mathrm{~K}$. The monolaurin was hydrolyzed to dodecanoic acid and glycerol, and then the dodecanoic acid was decomposed again. The decomposition of monolaurin in the subcritical state of 
water was studied with a programming of temperature heating where the reaction increased from ambient temperature to $623 \mathrm{~K}$ and without a catalyst.

King, Holliday, and List [26] discovered that they could achieve rapid hydrolysis of soybean oil for the formation of hexadecanoic, octadecanoic, octadeca-9-noic, octadeca-9,12-dienoic, and octadeca-9,12,15-trienoic acids in water in the supercritical state at different temperatures $(603-613 \mathrm{~K})$, the pressure of $13.1 \mathrm{MPa}$, and the ratio of water/oil ranged from 2.5:1 to 5:1. The hydrolysis occurred without catalyst and the volume of water in the reactor exceeded the volume of the triglycerides. They observed yields of free fatty acids (hexadecanoic, octadecanoic, octadeca-9-noic, octadeca-9,12-dienoic, and octadeca-9,12,15-trienoic acids) ranged from $90 \%$ to $100 \%$, for 10-15 min of reaction time and noted that the reaction was rapidly completed when water and triglycerides became a single phase at $613 \mathrm{~K}$. They noticed that hydrolysis under $603-613 \mathrm{~K}$ and $10-15 \mathrm{~min}$ produced some isomerized fatty acids from cis form to trans isomer.

Triglycerides can also be studied to obtain other products with higher added value such as long-chained hydrocarbons. The production of hydrocarbons, however, will be through reactions with fatty acids formed from the hydrolysis of triglycerides. Hossain et al. [27] reported the continuous conversion of octadeca-9-noic acid and other derivatives of fatty acid, such as castor oil, frying oil, and palm oil into n-paraffins. They used $10 \mathrm{wt} \%$ of $\mathrm{Mo}^{-} \mathrm{Al}_{2} \mathrm{O}_{3}, 10 \mathrm{wt} \%$ of $\mathrm{MgO}-\mathrm{Al}_{2} \mathrm{O}_{3}$, and $10 \mathrm{wt} \%$ of Ni- $\mathrm{Al}_{2} \mathrm{O}_{3}$ in subcritical water $(648 \mathrm{~K})$, time of $4 \mathrm{~h}$, and a water volume ratio for oleic acid was 5: 1 , without the addition of hydrogen. They found that $5 \mathrm{~g}$ of $10 \mathrm{wt} \% \mathrm{Mo}-\mathrm{Al}_{2} \mathrm{O}_{3}$ catalyst at $648 \mathrm{~K}$, with the ratio of water/oleic acid to 5:1 $(v / v)$ of, and $4 \mathrm{~h}$ exhibited a higher degree of decarboxylation of octadeca-9-noic acid with $92 \%$ and liquid yield $\left(\mathrm{C}_{14}, \mathrm{C}_{15}, \mathrm{C}_{16}, \mathrm{C}_{17}\right)$ with $71 \%$ compared to $\mathrm{MgO}-\mathrm{Al}_{2} \mathrm{O}_{3}$ and $\mathrm{Ni}-\mathrm{Al}_{2} \mathrm{O}_{3}$. Furthermore, selectivity for hydrocarbon was $34.8 \%$ tetradecane, $24 \%$ pentadecane, $22.9 \%$ hexadecane, and $18.3 \%$ heptadecane. Moreover, a significant quantity of amorphous carbon deposited on the $\mathrm{Mo}-\mathrm{Al}_{2} \mathrm{O}_{3}$ has been identified, and its removal can be carried out by simple calcination.

Obeid et al. [28] studied hydrothermal technology for various biomasses without a catalyst. Among them, sunflower oil was analyzed. The experiments were carried out at 200 bar, with the volume of compounds divided into $30 \%$ biomass and $70 \%$ water, temperatures of 523,573 , and $623 \mathrm{~K}$ and residence time varying up to $60 \mathrm{~min}$. They identified that treatment with hydrothermal technology resulted in a rise in the aqueous phase soluble compounds. After the hydrothermal reaction, gas oil, wax, lubricating, and vacuum gas decreased by about $20 \%$ for experiments at $623 \mathrm{~K}$. The results also showed that, with longer reaction times, conversion and degradation of fatty acids to lighter compounds occurred, resulting in higher yields for diesel-like products (478-563 K). After $60 \mathrm{~min}$ at $623 \mathrm{~K}, 70 \%$ of the sample was diesel and 10\% was gasoline and naphtha. The biocrude yield (gasoline, naphtha, kerosene, diesel, gas oil, wax, lubricating oil, and vacuum gas oil) at $623 \mathrm{~K}, 200 \mathrm{bar}$, and $1 \mathrm{~h}$ was $60 \%$, with a higher production of gas yield $(14 \%)$. Finally, they assumed that the heating rate of the reactor affects the yields of products due to the several chemical reactions that happen during the heat time of the reactor.

Kaur et al. [29] analyzed the hydrothermal processing of castor residue in batch. The ratio of biomass/water was $1 / 6$ ( $5 \mathrm{mg}$ of castor residue and $30 \mathrm{mg}$ of distilled water were loaded). The reaction temperatures were 533, 553, and $573 \mathrm{~K}$, and the reaction time was $15,30,60$, and $90 \mathrm{~min}$. No catalyst was used, and product separation was performed by vacuum filtration. The highest weight conversion was $83.80 \%$ at $553 \mathrm{~K}$ for $15 \mathrm{~min}$, while the lowest weight conversion was $75.25 \%$ at $533 \mathrm{~K}$ for $15 \mathrm{~min}$. The maximum total bio-oil (liquid fraction and final product after evaporation) yield of castor residue of $15.8 \mathrm{wt} \%$ was obtained at $573 \mathrm{~K}$ at $60 \mathrm{~min}$. The main compounds identified were categorized as phenolic compounds (benzene-1,4-diol, hydroquinone phenol, and p-cresol). Carbon recovery and energy recovery for the final product after evaporation were $24.23 \%$ and $31.08 \%$, respectively.

As clearly depicted previously, articles indicate the temperature of $627 \mathrm{~K}$ as the highest temperature deployed in most of the published literature. Notwithstanding, it was possible to find articles that used temperatures over $647 \mathrm{~K}$. Chen et al. [30] analyzed the hydrothermal conversion of sunflower oil with $8 \mathrm{wt} \%$ HZSM-5 catalyst $\left(\mathrm{SiO} 2 / \mathrm{Al}_{2} \mathrm{O}_{3}\right.$ : 50 ; pore diameter: $5 \AA$; surface area: $\left.425 \mathrm{~m}^{2} / \mathrm{g}\right)$, 
under different temperatures (623-773 K) and residence time of 20 min. HZSM-5 was calcinated at $723 \mathrm{~K}$ for $3 \mathrm{~h}$ and maintained in a desiccator during the tests. The oil yield varied from $12.41 \%$ to $18.89 \%$ as temperature ranged between 623 and $673 \mathrm{~K}$. The oil yield ranged from $12.41 \%$ to $18.89 \%$ as temperature increased between 623 and $673 \mathrm{~K}$. At $773 \mathrm{~K}$, the yield of the oil decreased to $12.41 \%$. The gas yield ranged from $16.48 \%$ to $32.41 \%$ with increasing temperature, too. They suggested that, at a low temperature $(623-723 \mathrm{~K})$, there was a favoring of products similar to diesel $\left(\mathrm{C}_{11}-\mathrm{C}_{20}\right)$ in the product slate, whereas at high-temperature, products similar to gasoline $\left(\mathrm{C}_{6}-\mathrm{C}_{11}\right)$ were observed. Moreover, the high temperature of $723 \mathrm{~K}$ favored the catalytic cracking of HZSM-5, which decreased the production of coal and helped in the elimination of the carbonyl group. Without HZSM, the content of alkanes varied from $40.62 \%$ to $54.61 \%$ (from 623 to $773 \mathrm{~K}$ ), and at $723 \mathrm{~K}$ the content of alkanes reached a maximum of $54.61 \%$. In the presence of the $8 \mathrm{wt} \% \mathrm{HZSM}$, the content of alkanes ranged between $43.57 \%$ and $56.27 \%$ (from 623 to $773 \mathrm{~K}$ ). Moreover, at $723 \mathrm{~K}$, a maximum of $56.27 \%$ of alkanes was achieved, occasioning in the highest heating value of $43.8 \mathrm{MJ} \mathrm{kg}^{-1}$. Finally, in the presence of $8 \mathrm{wt} \%$ HZSM-5, at $723 \mathrm{~K}$, alkanes reached a maximum of $56.27 \%$ (from sunflower oil with $2.28 \%$ of oxygen).

Nanda et al. [31] investigated the gasification hydrothermal from soybean oil residue to produce hydrogen. For this, different temperatures (648-948 K), concentrations of oil (25-40 wt $\%$ ), and residence times (15-60 min) were applied. The maximum hydrogen yield $\left(5.16 \mathrm{~mol} \mathrm{~kg}^{-1}\right)$ and total gases $\left(10.5 \mathrm{~mol} \mathrm{~kg}^{-1}\right)$ were acquired at the optimum temperature of $948 \mathrm{~K}$, with $25 \mathrm{wt} \%$ of waste soybean oil, in $60 \mathrm{~min}$ and without the presence of catalyst. This result showed that, while elevated temperatures benefited the water-gas shift reaction with higher $\mathrm{H}_{2}$ yield and the dehydrogenation of saturated molecules, high concentrations of raw material were conducted to methanation and produced higher yields of methane. Furthermore, it was analyzed that the use of $5 \mathrm{wt} \%$ of $\mathrm{Ru} / \mathrm{Al}_{2} \mathrm{O}_{3}$ catalyst increases $\mathrm{H}_{2}$ yield, while $5 \mathrm{wt} \%$ of $\mathrm{Ni} / \mathrm{Si}-\mathrm{Al}_{2} \mathrm{O}_{3}$ improves methane yield through methanation and hydrogenation reactions. In total, $5 \mathrm{wt} \% \mathrm{Ru} / \mathrm{Al}_{2} \mathrm{O}_{3}$ at $948 \mathrm{~K}, 60 \mathrm{~min}, 23-25 \mathrm{MPa}$, and $25 \mathrm{wt} \%$ of waste soybean oil produced $21.4 \mathrm{~mol} \mathrm{~kg}^{-1}$ of total gas yields and $90 \%$ selectivity for hydrogen. Meanwhile, $5 \mathrm{wt} \%$ $\mathrm{Ni} / \mathrm{Si}_{-} \mathrm{Al}_{2} \mathrm{O}_{3}$ at $948 \mathrm{~K}, 60 \mathrm{~min}, 23-25 \mathrm{MPa}$, and $25 \mathrm{wt} \%$ of waste cooking oil produced $21.71 \mathrm{~mol} \mathrm{~kg}^{-1}$ of total gas yields, $74 \%$ selectivity for hydrogen. They also proved that the ionic mechanism (quasi-critical pressures and temperature $<400{ }^{\circ} \mathrm{C}$ ) and free radical mechanism (temperature $>400{ }^{\circ} \mathrm{C}$ ) prevail in the supercritical system. Finally, they identified the main products in the processing of waste cooking oil at elevated temperatures, namely methanol, phenol, acetone, hydroxyacetone, and glycerol.

As far as selectivity is concerned, Robin, Jones, and Ross [15] studied hydrothermal processes for sunflower, soybean, jatropha, palm, and linseed oils with temperature ranging from 523 to $623 \mathrm{~K}$ and pressure ranging from 12 to $17 \mathrm{MPa}$. They used $0.5 \mathrm{~g}$ of catalyst, $3 \mathrm{~g}$ of triglycerides (sunflower, soybean, linseed, jatropha, and palm oils), and $27 \mathrm{~cm}^{3}$ of water during hydrothermal reactions. They proved that, below $523 \mathrm{~K}$, hydrolysis converted triglycerides into free fatty acids and glycerol. Additionally, $0.5 \mathrm{~g}$ of MoZSM- 5 and $0.5 \mathrm{~g}$ of HZSM- 5 catalysts at $623 \mathrm{~K}$ were more selective for the production of lighter gasoline fractions and lighter kerosene fractions range $\mathrm{C}_{8}-\mathrm{C}_{12}$, o-xylene, decene, 1-ethyl-2-methyl-benzene, 1-methyl-2-methylene-cyclohexane, and 1-methyl-3-hexyl-benzene, whereas $0.5 \mathrm{~g}$ of FeZSM- 5 at $623 \mathrm{~K}$ promoted the formation of a heavier diesel fraction. The highest yield of gasoline fraction was for the $0.5 \mathrm{~g}$ MoZSM- 5 catalyst $(16.1 \%)$ at $623 \mathrm{~K}$.

Concerning the main product formed in hydrothermal conversion of vegetable oil, most of the processes focus on the formation of heptadecane. Sugami, Minami, and Saka [32] converted $0.9 \mathrm{~g}$ of rapeseed oil at $543 \mathrm{~K}$ and $0.05-0.45 \mathrm{~g}$ of $\mathrm{Pd} / \mathrm{C}$ through two stages (hydrothermal hydrolysis/hydrogenation and decarboxylation) and produced pentadecane, n-heptadecane, and n-nonadecane, which would correspond to the main composition of the formulated diesel. They observed that, at a temperature of $543 \mathrm{~K}$ and $5 \mathrm{MPa}$, with $3 \mathrm{~g}$ of water and $0.05 \mathrm{~g}$ of $\mathrm{Pd} / \mathrm{C}$ for 20 and $40 \mathrm{~min}$, diglycerides and monoglycerides were designated as intermediate products. However, for $60 \mathrm{~min}, 543 \mathrm{~K}, 0.05 \mathrm{~g} \mathrm{Pd} / \mathrm{C}$, and $3 \mathrm{~g}$ of water, the glycerides were at the same time hydrolyzed and hydrogenated to produce saturated fatty acids $\left(\mathrm{C}_{16}, \mathrm{C}_{18}\right.$, and $\left.\mathrm{C}_{20}\right)$ in a yield of $96.1 \mathrm{~mol} \%$ and into glycerides in a yield of $2.3 \%$. At $573 \mathrm{~K}$ with $0.45 \mathrm{~g}$ of $\mathrm{Pd} / \mathrm{C}$ and after $120 \mathrm{~min}$, the saturated 
fatty acids underwent decarboxylation reaction to form hydrocarbons (pentadecane, heptadecane, and nonadecane) with a yield of $91.5 \mathrm{~mol} \%$.

Jin and Choi [33] investigated the hydrothermal deoxygenation of the palm oil at 448, 473,498, 523 , and $558 \mathrm{~K}$, using $0.92 \mathrm{~g}$ of PtRe supported on various carbons. For the reaction, they used $20 \mathrm{~g}$ of palm oil, $80 \mathrm{~g}$ of water, and the catalysts were pre-reduced at $573 \mathrm{~K}$. The residence time was $24 \mathrm{~h}$. When $0.92 \mathrm{~g}$ of Pt/CNT (carbon nanotubes) catalyst was used, n-paraffins (pentadecane, hexadecane, heptadecane, and octadecane) were produced above $523 \mathrm{~K}$, being $43 \mathrm{~mol} \%$ of pentadecane and $53 \%$ mol of heptadecane, and the sum of hexadecane and octadecane was inferior to $4 \mathrm{~mol} \%$. For $0.92 \mathrm{~g}$ of $\mathrm{PtRe} / \mathrm{CNT}$ at $558 \mathrm{~K}$, the n-paraffins produced mainly contained pentadecane $(49 \mathrm{~mol} \%)$ and heptadecane (47 mol\%), and the sum of the $\mathrm{C}_{16}$ and $\mathrm{C}_{18}$ was less than $2 \mathrm{~mol} \%$. Moreover, the quantity of $n$-paraffin in the oil phase at $558 \mathrm{~K}(88 \mathrm{C} \%)$ and with $0.92 \mathrm{~g}$ of PtRe/CNT was significantly superior to $0.92 \mathrm{~g}$ $\mathrm{Pt} / \mathrm{CNT}(16 \mathrm{C} \%)$. Due to the predominance of $\mathrm{C}_{15}$ and $\mathrm{C}_{17}$, they concluded that the main formation of paraffins was by deoxygenation. Finally, at $558 \mathrm{~K}, \mathrm{PtRe} / \mathrm{CNT}$ demonstrated the best result to produce n-paraffins $\left(\mathrm{C}_{15}-\mathrm{C}_{18}\right)$ from palm oil with yield $72 \mathrm{wt} \%$ (theoretical yield: $79 \mathrm{wt} \%$ ), and it could be recycled for five cycles, with calcination $(573 \mathrm{~K}$ ), without significant loss of activity (from 72 to $66 \mathrm{wt} \%$ ). In abstaining of calcination, the yield of n-paraffin $\left(C_{15}-C_{18}\right)$ reduced from $72 \mathrm{wt} \%$ to $16 \mathrm{wt} \%$ after three reaction cycles.

\subsubsection{Fatty Acids}

Fatty acids have been deployed as a raw material in hydrothermal methods to generate long-chain hydrocarbons. Yang et al. [34] examined hydrothermal decarboxylation of $0.176 \mathrm{mmol}$ stearic, palmitic, arachidonic, and behenic acids, present in the microalga oil, and using $10 \mathrm{mg}$ of Pt/Nanotube $\mathrm{C}$, $\mathrm{Pd} / \mathrm{C}, \mathrm{Ru} / \mathrm{W}$, and water. The conversion of stearic acid for decarboxylation at $603 \mathrm{~K}$ for $30 \mathrm{~min}$ and $10 \mathrm{mg} \mathrm{Pt} / \mathrm{MWCNTs}, \mathrm{Pt} / \mathrm{C}$, and $\mathrm{Ru} / \mathrm{C}$ was $52.4 \pm 2.4 \%, 52.4 \pm 2.5 \%$, and $42.3 \pm 5.2 \%$, respectively. Their selectivities to $\mathrm{C}_{17}$ were $97.0 \pm 4.4 \%, 57.0 \pm 2.7 \%$, and $42.9 \pm 3.6 \%$, respectively. Stearic acid decarboxylation over $\mathrm{Pt} / \mathrm{C}$ detected a large number of secondary products by GC-MS, such as $\mathrm{C}_{13}$, $\mathrm{C}_{14}, \mathrm{C}_{15}, \mathrm{C}_{16}, \mathrm{C}_{20}$, E-14-hexadecenal, and 2-methyl-7-hexadecene. The conversion of stearic acid raised with the reaction time when temperature ranged from 543 to $603 \mathrm{~K}$. At $633 \mathrm{~K}$, the conversion of stearic acid ranged from $56 \%$ (15 $\mathrm{min}$ ) to $85 \%$ (45 $\mathrm{min}$ ) and then reached $90 \%$ (90 $\mathrm{min}$ ). Moreover, all experiments detected undesired products such as hexadecane, hexadecenal, and heptadecene. They established that the consumption rate of stearic acid was a first-order and the rate constant was $0.127 \pm 0.008,0.809 \pm 0.035,2.456 \pm 0.092$, and $4.571 \pm 0.388 \times 10^{-2} \mathrm{~min}^{-1}$ at $543,573,603$, and $633 \mathrm{~K}$, respectively. Finally, they concluded that the optimum reaction for stearic acid used $10 \mathrm{mg}$ of catalyst load, $50 \mathrm{mg}$ of stearic acid, at $603 \mathrm{~K}$, and after $60 \mathrm{~min}$. Other experiments were performed using $0.176 \mathrm{mmol}$ of dodecanoic, tetradecanoic, hexadecanoic, octadecanoic, eicosanoic, and docosanoic acids, which were decarboxylated with $10 \mathrm{mg}$ Pt/MWCNTs, at $603 \mathrm{~K}$ and after $60 \mathrm{~min}$. All feedstock reached high conversion over Pt/MWCNTs, around $75 \%$. On the other hand, the selectivities to $\mathrm{C}_{17}$ from dodecanoic, tetradecanoic, hexadecanoic, and octadecanoic acids were much higher than eicosanoic and docosanoic acids.

Mo, Tandar, and Savage [19] investigated the reactions of palmitic, stearic, oleic, and linoleic acids in supercritical water at $673 \mathrm{~K}, 240 \mathrm{bar}$, and $180 \mathrm{~min}$. The main catalysts used were zeolites $\mathrm{Y}$, beta, and ZSM-5. In total, $150 \mathrm{mg}$ of fatty acid, $150 \mathrm{mg}$ of catalyst, and $0.6 \mathrm{~mL}$ of water were loaded into each reactor. Control experiments involved reactions with palmitic, stearic, oleic e linoleic acids, and water and occurred without catalyst at $673 \mathrm{~K}$ and for $180 \mathrm{~min}$. The conversions were $34 \pm 5 \%$, $54 \pm 8 \%, 22 \pm 11 \%$, and $80 \pm 18 \%$, respectively. The total yield of liquid products from palmitic, stearic, oleic, and linoleic acid was $12 \pm 5,7 \pm 2,19 \pm 12$, and $41 \pm 5 \mathrm{wt} \%$, respectively. Xylenes, toluene, and 2-methyl-pentane were the major products of liquid products. Moreover, they reacted hexadecanoic acid over zeolites beta (silica/alumina $=38,300$ ), ZSM-5 (silica/alumina $=30$ ), and Y (silica/alumina $=60$ ) in supercritical water at $673 \mathrm{~K}, 240 \mathrm{bar}$, for $180 \mathrm{~min}$. ZSM-5 had the highest conversion of $95 \pm 4 \%$. The lowest conversion of hexadecanoic acid was $30 \%$ and occurred with 
zeolite beta, and the conversion of hexadecanoic acid with zeolite $Y$ was about $50 \%$. Zeolites beta and Y produced 2-methyl-pentane, while ZSM-5 formed toluene (molar yield was $22 \pm 3 \%$ ) and xylenes (molar yield was $49 \pm 8 \%$ ). The highest total yield of liquid and gaseous products was $97 \mathrm{wt} \%$ and was produced from palmitic acid, using ZSM- 5 with a ratio of silica/alumina equal to 23 at $673 \mathrm{~K}$ and 240 bar.

Miao et al. [35] studied the catalytic deoxygenation of hexadecanoic acid to generate paraffin. For this, they used $500 \mathrm{mg}$ of $\mathrm{Ni} / \mathrm{ZrO}_{2}$ with absent or low external pressure (100 psi), $500 \mathrm{mg}$ of palmitic acid, and $4.5 \mathrm{~mL}$ of deionized water. The results showed that the existence of water greatly improved the conversion of hexadecanoic acid, paraffin efficiency, and eliminate the secondary reactions of ketonization and esterification, which was related to $\mathrm{H}_{2}$ formation in situ. In the presence of water at $573 \mathrm{~K}, 10 \% \mathrm{Ni} / \mathrm{ZrO}_{2}(0.5 \mathrm{~g}), 6 \mathrm{~h}$, and with absent of external hydrogen supply, the conversion of hexadecanoic acid was $17.2 \% \mathrm{C}$ and the paraffin yield was $1.8 \% . \mathrm{C}_{15}$ and other short paraffins $\left(\mathrm{C}_{9}-\mathrm{C}_{14}\right)$ were the main products formed in the experiments.

Zhang et al. [36] analyzed the catalytic decarboxylation and aromatization of $50 \mathrm{mg}$ of and oleic acid, using $30 \mathrm{mg}$ of $\mathrm{Ni} / \mathrm{AC}$ catalyst (nickel on activated carbon) with temperatures of $603,623,643$, and $663 \mathrm{~K}$, and a residence time of $4 \mathrm{~h}$, and without $\mathrm{H}_{2}$ or solvents. They observed that octadecanoic acid efficiency reduced steadily when the temperature increased. Moreover, coke was the main by-product formed. They attributed coke formation to high-temperature conditions in the reactions. They studied the catalytic decarboxylation and aromatization of $0.176 \mathrm{mmol}$ of oleic acid over Ni/AC with different $\mathrm{Ni}$ loadings at $623 \mathrm{~K}$ and $4 \mathrm{~h}$. The total yield of $\mathrm{C}_{17}$ and aromatics ranged from $8.4 \%$ to $44.8 \%$ when the loading of Ni/AC increased from $10 \%$ to $30 \%$ and decreased to $39.8 \%$ when the loading of $\mathrm{Ni} / \mathrm{AC}$ reached $40 \%$. In addition, they analyzed the catalytic decarboxylation and aromatization of at $623 \mathrm{~K}, 30 \mathrm{mg} \mathrm{Ni} / \mathrm{AC}$ catalyst, and four hours. The main products were heptadecane, aromatics, and coke, and the molar carbon yield was $38.4 \%, 13.0 \%$, and $29.9 \%$, respectively.

Edeh, Overton, and Bowra [37] evaluated the temperature and time on hydrothermal deoxygenation of $100 \mathrm{mg}$ of palmitic and oleic acids under subcritical conditions using a $5 \%(20 \mathrm{mg})$ of $\mathrm{Pd} / \mathrm{C}$, and $15 \mathrm{~mL}$ distilled water. They concluded that the highest conversion of hexadecanoic acid reached was $71.7 \%$ at $563 \mathrm{~K}$ and one hour, whereas a minimum was $66.3 \%$ achieved after $1.5 \mathrm{~h}$ and $563 \mathrm{~K}$. The maximum selectivity of $\mathrm{C}_{15}$ was $54.6 \%$, and the lowest was $8.1 \%$, while the highest selectivity of $\mathrm{C}_{17}$ was $4.9 \%$, and the lowest was $2.9 \%$, with both obtained at $563 \mathrm{~K}$ after 1.5 and $0.5 \mathrm{~h}$, respectively. For four hours of reaction, the maximum selectivity of $\mathrm{C}_{15}$ was $24.4 \%$ and the lowest $6.8 \%$, while those of $\mathrm{C}_{17}$ were $3.3 \%$ and $2.3 \%$, with all acquired at 563 and $603 \mathrm{~K}$, respectively. For oleic acid, the maximum and minimum conversions with $4 \mathrm{~h}$ of reaction were $88.1 \%$ and $73.3 \%$, obtained at 603 and $563 \mathrm{~K}$, respectively. For four-hour reaction time, the selectivities for $C_{15}$ were $4.1 \%$ and 3.2\% at 603 and $563 \mathrm{~K}$, and for $\mathrm{C}_{17}$, they were $16.9 \%$ and $14.7 \%$ at 603 and $563 \mathrm{~K}$, respectively. Regarding residence time at $563 \mathrm{~K}$, the maximum selectivity to $C_{15}$ was $9.2 \%$ after $1 \mathrm{~h}$, and the lowest was $5.8 \%$ after $3 \mathrm{~h}$. For $\mathrm{C}_{17}$, the highest and lowest selectivities were $13.6 \%$ and $10.0 \%$ at 1 and $0.5 \mathrm{~h}$, in that order. When the influence of residence time is evaluated at $563 \mathrm{~K}$, maximum and minimum conversions of $61.2 \%$ at $3 \mathrm{~h}$ and $47.8 \%$ at $0.5 \mathrm{~h}$ were found. Furthermore, the highest selectivity for $\mathrm{C}_{15}$ was $9.2 \%$ after $1 \mathrm{~h}$, and the lowest was $5.8 \%$ at $563 \mathrm{~K}$ and after $3 \mathrm{~h}$.

Zhang et al. [38] studied the hydrothermal decarboxylation and cracking of stearic acid and 1,2-distearoyl-3-palmitoyl-sn-glycerol, varying residence time with $5 \mathrm{wt} \%$ of $\mathrm{Ru} / \mathrm{C}$, water, the temperature of $603 \mathrm{~K}$, and with in situ $\mathrm{H}_{2}$ generation. The in situ production of hydrogen in hydrothermal reactions of octadecanoic acid was analyzed with a molar yield $(\mathrm{mol} \%$, $\mathrm{n}$ (hydrogen)/n(octadecanoic acid) $\times 100 \%$ ) increasing from $56.7 \%$ after $2.5 \mathrm{~h}$ to $92 \%$ after $12.5 \mathrm{~h}$. The complete conversion of octadecanoic acid was observed within $12.5 \mathrm{~h}$ with selectivity for n-heptadecane equal to $59.2 \pm 3.2 \%$ and selectivity for n-octadecane equal to $0.3 \pm 0.3 \%$. The maximum selectivity found for $\mathrm{C}_{17}$ and $\mathrm{C}_{18}$ were $65.8 \%$ and $1.9 \%$, respectively, after $7.5 \mathrm{~h}$. They identified that most of the products of hydrothermal decarboxylation and cracking of octadecanoic acid with $\mathrm{Ru} / \mathrm{C}$ at $603 \mathrm{~K}$ were $C_{7}$ to $C_{17}$ alkanes, along with small quantities of gaseous products $\left(C_{1}-C_{5}\right.$ alkanes 
$\left.+\mathrm{CO}_{2}\right) \cdot \mathrm{C}_{17}$ was the main compost, but small quantities of $\mathrm{C}_{18}$ were also observed following a hydrodeoxygenation pathway. The main gaseous products yielded were $\mathrm{CO}_{2}, \mathrm{CH}_{4}$, and $\mathrm{H}_{2}$.

Mo and Savage [39] explored the hydrothermal process by using $150 \mathrm{mg}$ hexadecanoic acid in the presence of $150 \mathrm{mg}$ of zeolite HZSM-5, $0.6 \mathrm{~mL}$ of deionized water in a batch reactor and above $673 \mathrm{~K}$, $240 \mathrm{bar}$, and with a residence time of $180 \mathrm{~min}$. The conversion of hexadecanoic acid at $673 \mathrm{~K}$ was the first-order kinetics, and the rate constant was $2.6 \times 10^{-4} \mathrm{~s}^{-1} \pm 3.8 \times 10^{-6} \mathrm{~s}^{-1}$. The maximum yield of liquid products was $73 \%$ and occurred at $673 \mathrm{~K}$, after $180 \mathrm{~min}$, with $0.1 \mathrm{~g} \mathrm{~mL}^{-1}$ of water, and without hydrogen $\mathrm{H}_{2}$. The main liquid products were aromatic hydrocarbons (e.g., xylenes and toluene) and alkanes (e.g., 2-methyl-pentane and heptane). The main gaseous products were carbon monoxide and carbon dioxide, but considerable yields of $\mathrm{C}_{3} \mathrm{H}_{8}$ e and $\mathrm{C}_{4} \mathrm{H}_{10}$ were also produced.

Furthermore, it was possible to find studies with temperatures below $523 \mathrm{~K}$. Khuwijitjaru, Adachi, and Matsuno [40] analyzed the solubility of capric, myristic, palmitic, and stearic acids with different temperatures (333-503 K) and pressure of 5-15 MPa. They concluded that the temperature has no influence on this physical property and the solubility is directly proportional to the increase in temperature. Likewise, they concluded that the solubility is also directly in proportion with the chain size of the molecules. In other words, the higher the temperature and the longer the chain, the greater its solubility.

Khuwijitjaru et al. [41] analyzed the hydrolysis of methyl octanoate, methyl decanoate, methyl laurate, methyl myristate, and methyl palmitate in subcritical water when the temperature ranged from 483 to $543 \mathrm{~K}$. All fatty acid esters followed first-order kinetics on all temperatures. They observed the presence of a steric hindrance of the acyl or alkyl chain in the hydrolysis reaction, which indicated higher apparent activation energy for the hydrolysis for those compounds. Additionally, they noted that the methyl laurate was hydrolyzed faster than the butyl laurate at $483,503,523$, and $543 \mathrm{~K}$. Another study by Khuwijitjaru et al. [42] analyzed the solubility of oleic and linoleic acids, with different temperatures (333-503 K) and pressure of $15-20 \mathrm{MPa}$. They used $10 \mathrm{~mL}$ of fatty acid, $5 \mathrm{~mL}$ of water, and no catalyst. They observed that solubilities of oleic and linoleic acids were almost the same when temperature increased from 333 to $503 \mathrm{~K}$. Moreover, at $15 \mathrm{MPa}$ and with temperature ranging from 333 to $503 \mathrm{~K}$, solubilities of oleic and linoleic acids were slightly higher than palmitic acid. Finally, they estimated the enthalpy of the solution of oleic and linoleic acids in the liquid state in water to be $122 \mathrm{~kJ} \mathrm{~mol}^{-1}$ when the temperature was above $423 \mathrm{~K}$.

There are studies with hydrothermal technology that use homogeneous catalysts. An example is Watanabe et al. [43], who studied the decomposition of $0.3 \mathrm{~g}$ of stearic acid with $1 \mathrm{~g}$ of water at $673 \mathrm{~K}$ in a batch reactor. The residence time increased from 15 to $120 \mathrm{~min}$. They studied the decomposition of stearic acid at $673 \mathrm{~K}, 30 \mathrm{~min}$, and $0.3 \mathrm{~g}$ of $\mathrm{CeO}_{2}, \mathrm{Y}_{2} \mathrm{O}_{3}$, and $\mathrm{ZrO}_{2}$. The conversions of stearic acid by using $\mathrm{CeO}_{2}$ was $30 \%, \mathrm{Y}_{2} \mathrm{O}_{3}$ was $62 \%$, and $\mathrm{ZrO}_{2}$ was $68 \%$. They did the same experiment with the addition of $0.3 \mathrm{~g}$ of $\mathrm{NaOH}$ or $\mathrm{KOH}$ and realized that this led to an increase in the degradation of octadecanoic acid and the $\mathrm{C}_{17}$ being the major product. At $673 \mathrm{~K}$ and $30 \mathrm{~min}$, the conversion of stearic acid in $\mathrm{NaOH}(13 \%)$ was six times higher than that without $\mathrm{NaOH}(2 \%)$. For $0.3 \mathrm{~g}$ of $\mathrm{KOH}$, at $673 \mathrm{~K}$ and $30 \mathrm{~min}$, the conversion of octadecanoic acid was $32 \%$ and in the absence of $\mathrm{KOH}$ was $2 \%$. Besides that, $\mathrm{KOH}$ had a greater decomposition effect than $\mathrm{NaOH}$.

Even though hydrothermal studies use homogeneous catalysts in the form of alkaline salts, it is possible to find the use of heterogeneous catalysts. Additionally, there is the adoption of solid acid catalysts such as the zeolites. As an example, for acid catalysts, Mo, Tandar, and Savage [19] used HZSM- 5 as a catalyst for the supercritical hydrothermal treatment of palmitic acid and analyzed how the ratio of silica/alumina affects the results of hydrothermal reaction. They conducted experiments at $673 \mathrm{~K}, 240$ bar, and $180 \mathrm{~min}$ with $150 \mathrm{mg}$ palmitic acid and $150 \mathrm{mg}$ HZSM-5 with different ratios of silica/alumina $(23,30,50$, and 80$)$. HZSM- 5 with a ratio of silica/alumina equal to 23 obtained the maximum total product yield of $97 \pm 2 \mathrm{wt} \%$ and the maximum conversion of $98 \pm 1 \%$. As the ratio of silica/alumina reduced, the yields of toluene and xylenes increased. The ratio of silica/alumina equal to 23 resulted in a $66 \%$ yield of xylenes, $25 \%$ yield of toluene, and $102 \%$ total molar yield of single-ring 
aromatics. Consequently, they demonstrated that, when the zeolite has a low Silica/Alumina ratio, there is a greater selectivity for the formation of BTX aromatics (benzene, toluene, and xylene) if compared to the higher Silica/Alumina ratio.

Watanabe et al. [43], for example, investigated the effect of $0.3 \mathrm{~g}$ of zirconia $\left(\mathrm{ZrO}_{2}\right)$ on $0.3 \mathrm{~g}$ of stearic acid under semi-hydrothermal conditions at $673 \mathrm{~K}$ and $25 \mathrm{MPa}$ for $30 \mathrm{~min}$. In this study, $\mathrm{ZrO}_{2}$ reinforced the conversion of stearic acid $(68 \%)$ and that its major products were $\mathrm{C}_{16}$-alkene, acetic acid, and 2-Nonadecanone. Robin et al. [44] also performed another interesting study, which analyzed the inclusion of transition metals to HZSM- 5 by ion exchange or impregnation. They noted that metal-doped ZSM- 5 catalysts were less stable when prepared by impregnation than metal-doped ZSM- 5 catalysts were prepared with ion exchange. They concluded that HZSM-5 and MoZSM- 5 have good activity in the conversion of sunflower oil into alkenes and aromatic molecules. In addition, MoZSM- 5 favored the production of aromatic compounds from sunflower oil. They also studied the regeneration of HZSM-5. For the regeneration experiments, $3 \mathrm{~g}$ of sunflower oil, $0.5 \mathrm{~g}$ of HZSM-5, and $27 \mathrm{~mL}$ of deionized water were used at $623 \mathrm{~K}$ for $1 \mathrm{~h}$. They observed that HZSM- 5 was stable during the recycling procedure, since the bio-crude yield increased from cycle $1(40.3 \%)$ to cycle $2(43.3 \%)$, and afterward the bio-crude yield was the same with stage $3(43.1 \%)$. Robin, Jones, and Ross [15] concluded that the use of zeolites (mainly doped with Mo) can break down fractions of triglycerides and increase the fraction of gasoline, which in the end develops the flow properties of the resulting oils. In fact, zeolites benefit catalytic cracking to generate aromatic substances and aliphatic hydrocarbons. They studied hydrothermal processes for sunflower oil ( $3 \mathrm{~g})$ at $623 \mathrm{~K}$ and $27 \mathrm{~cm}^{3}$ of water. The gasoline yield (16.1\%) for the doped MoZSM- 5 catalyst $(0.5 \mathrm{~g})$ was higher than the gasoline yield $(8.8 \%)$ for HZSM-5 (0.5 g) without metal doping. The metal-doped catalysts also affect the fraction of diesel. Typically, the existence of a zeolite decreases the diesel-like fraction, except for FeZSM-5, which increases the formation of the diesel fraction. However, the bio-crude still requires an upgrade step, the hydrogenation.

Some researchers have studied the regeneration of metal catalysts. For example, Hossain et al. [45] explored the thermal regeneration of activated carbon with the presence of potassium hydroxide $(\mathrm{KOH})$ at $1023 \mathrm{~K}$ in the hydrothermal process of oleic acid. The activated carbon catalyst was removed from the reactor and then washed many times with hexane. Activated carbon was introduced in a vacuum oven at $353 \mathrm{~K}$ all night. Regeneration of the catalyst was executed by mixing with $\mathrm{KOH}(300 \mathrm{wt} \%)$. Activated carbon with $\mathrm{KOH}$ was heated in a tubular furnace at $1023 \mathrm{~K}$ for $3 \mathrm{~h}$. The sample was removed from the oven, and a dilute solution of $\mathrm{HNO}_{3}$ was added to neutralize the $\mathrm{KOH}$. The mixture of activated carbon with $\mathrm{HNO}_{3}$ was centrifuged. Water was added to the activated carbon to remove any residual $\mathrm{KOH}$ or $\mathrm{HNO}_{3}$. The wet solid was introduced again in a vacuum oven at $353 \mathrm{~K}$ for $12 \mathrm{~h}$. The hydrothermal decarboxylation of oleic acid happened at $673 \mathrm{~K}$, the ration of water/oleic acid was $4: 1$, and the time was $2 \mathrm{~h}$. In total, $4 \mathrm{~g}$ of catalyst was used for each experiment. They concluded that this regeneration method helped to recover the physical and catalytic properties of activated carbon, since $87 \%$ of the BET surface area was recovered after regeneration. Moreover, the degree of decarboxylation of oleic acid using fresh activated carbon was $91 \%$, and using regenerated activated carbon was $87 \%$. Experiments conducted with activated carbon after the second regeneration demonstrated that the degree of decarboxylation was $81 \%$. The selectivity of heptadecane using activated carbon after the second regeneration was also a little lower $(78.3 \%)$ compared to the value using fresh activated carbon $(89.3 \%)$ and activated carbon after the first regeneration $(81.2 \%)$.

Mo and Savage [39] observed the possibility of regenerating the catalyst by removing the coke via oxidation and by calcination to restore its structure. They identified aromatic hydrocarbons (xylenes and toluene) and alkanes (2-methyl pentane and heptane) as principal products of hydrothermal processes using palmitic acid in the presence of zeolite HZSM-5, above $673 \mathrm{~K}$ and with a reaction time of $180 \mathrm{~min}$. They concluded that controlled oxidation and calcination could be used to regenerate $150 \mathrm{mg}$ of HZSM-5. The total product yield (xylenes, toluene, 2-methyl-pentane, heptane, $\mathrm{CO}, \mathrm{CO}_{2}$, propane, and butane) reduced from $76 \pm 13 \mathrm{wt} \%$ to $53 \pm 1.9 \mathrm{wt} \%$ when the utilization of catalyst 
ranged from fresh catalyst to not fresh upon the second use of catalyst. In the hydrothermal catalytic cracking was used $150 \mathrm{mg}$ hexadecanoic acid, $150 \mathrm{mg}$ of HZSM-5 at $673 \mathrm{~K}, 240 \mathrm{bar}, 180 \mathrm{~min}$, and $0.15 \mathrm{~g}$ $\mathrm{mL}^{-1}$ water. For regeneration, HZSM- 5 was heated at $343 \mathrm{~K}$ overnight. Next, was realized controlled combustion (heating at $2{ }^{\circ} \mathrm{C} \mathrm{min}^{-1}$ to $823 \mathrm{~K}$ ) in the air to burn off any coke. The $823 \mathrm{~K}$ temperature was then maintained for $4 \mathrm{~h}$, to calcine the HZSM-5, after which the material naturally cooled to room temperature.

Mo, Tandar, and Savage [19] observed the possibility of regenerating HZSM-5. They proved that HZSM- 5 could be regenerated and reused three times through controlled combustion (heating in air at $2{ }^{\circ} \mathrm{C} \mathrm{min}^{-1}$ up to $823 \mathrm{~K}$, and maintaining at $823 \mathrm{~K}$ for $4 \mathrm{~h}$ ). The hydrothermal reaction to study the regeneration used $150 \mathrm{mg}$ of HZSM-5, the ratio of silica/alumina was $23,150 \mathrm{mg}$ of palmitic acid, $0.6 \mathrm{~mL}$ of water at $673 \mathrm{~K}, 180 \mathrm{~min}$, and $240 \mathrm{bar}$ and obtained a total product yield (gas plus liquid) of $76 \pm 3 \mathrm{wt} \%$ (which contains $40 \pm 5$ molar yield of xylenes).

As far as selectivity is concerned, most articles show heptadecane as the most selective product from the hydrothermal reactions of oleic and stearic acids. Al Alwan, Salley, and Ng [18] studied the hydrothermal decarboxylation of $0.156 \mathrm{mmol}$ of octadec-9-enoic acid to generate hydrocarbons present in diesel fraction, without the introduction of hydrogen, with the residence time of four hours, and temperature of $623 \mathrm{k}$ (subcritical condition) or $673 \mathrm{~K}$ (supercritical condition). Moreover, $10 \mathrm{mg}$ of some Ni-based transition metal carbide catalysts supported on Al-SBA-15 and $0.642 \mathrm{~mL}$ of water was used in the reactions. The conversion under subcritical conditions with $\mathrm{NiMoC}, \mathrm{NiNbC}$, NiWC, and NiZrC was $13.1 \%, 15.3 \%, 15.6 \%$, and $12.9 \%$, respectively. Their corresponding selectivities to unsaturated $\mathrm{C}_{17}$ were $34.6 \%, 31.1 \%, 35.8 \%$, and $28.5 \%$, respectively. The major products under subcritical conditions were oxygenated substances, with no measurable quantity of octadecanoic acid. The conversion under supercritical conditions with $\mathrm{NiMoC}, \mathrm{NiNbC}, \mathrm{NiWC}$, and $\mathrm{NiZrC}$ were $32.8 \%$, $30.7 \%, 30.7 \%$, and $30.1 \%$, respectively. Their corresponding selectivities to unsaturated $\mathrm{C}_{17}$ were $62.5 \%, 67.6 \%, 53.6 \%$, and $67.7 \%$, respectively. The maximum conversion of octadec-9-enoic acid and selectivity for $\mathrm{C}_{17}$ was $97.3 \%$ and $5.2 \%$ after adding $0.48 \mathrm{mmol}$ glycerol under supercritical conditions ( $673 \mathrm{~K}, 10 \mathrm{mg}$ of NiWC, $0.642 \mathrm{~mL}$ of water, and four hours). Besides heptadecane, $\mathrm{C}_{10}-\mathrm{C}_{16}$ were also formed, and they suggested that the NiWC/Al-SBA-15 catalyst demonstrated catalytic cracking under supercritical conditions.

Hossain et al. [45] investigated the stability and surface chemistry of activated carbon for the decarboxylation of octadec-9-enoic acid $(5 \mathrm{~g})$ in a continuous reactor at $673 \mathrm{~K}$, and the ratio of water/oleic acid was 4:1. In total, $4 \mathrm{~g}$ of activated carbon was used for each experiment. For $2 \mathrm{~h}$, the degree of decarboxylation was $91 \%$, and the selectivity of $C_{17}$ was $89.3 \%$. After 10,20 , and $30 \mathrm{~h}$, the degrees of decarboxylation were $91 \%, 90 \%$, and $88.9 \%$. When the residence time increased from 10 to $30 \mathrm{~h}$, the selectivity of $C_{8}-C_{16}$ increased from $10.2 \%$ to $13.4 \%$, while the selectivity of $C_{17}$ reduced from $89.3 \%$ to $86 \%$. Above $30 \mathrm{~h}$, they observed the activated carbon performance was effective and increased the degree of decarboxylation from $88.9 \%$ to $60 \%$ when the reaction time ranged from 30 to $40 \mathrm{~h}$. After $45 \mathrm{~h}$, the degree of decarboxylation and the selectivity to $\mathrm{C}_{17}$ reached $50 \%$ and $34 \%$, respectively. The drop in both activity and selectivity was connected to the deactivation of the activated carbon.

$\mathrm{Fu}, \mathrm{Lu}$, and Savage [46] analyzed the catalytic hydrothermal deoxygenation of $0.176 \mathrm{mmol}$ of hexadecanoic, dodecanoic, octadecanoic, and oleic acids by using $5 \% \mathrm{Pt} / \mathrm{C}$ and $5 \% \mathrm{Pd} / \mathrm{C}$ at $603 \mathrm{~K}$. No hydrogen was added. They found selectivity greater than $90 \%$ for hydrocarbons in the hydrothermal hydrogenation and decarboxylation of hexadecanoic, dodecanoic, and octadecanoic acids. Besides this, they noted that the rate of decarboxylation is independent of the number of carbons in the fatty acid. For oleic acid with $\mathrm{Pt} / \mathrm{C}$ at $603 \mathrm{~K}$ and 1 hour, no $\mathrm{C}_{17}$ was detected, and the yield to stearic acid was $4 \%$. For the reaction of oleic acid with $\mathrm{Pt} / \mathrm{C}$ at $603 \mathrm{~K}$ and after $1.5 \mathrm{~h}$, the yield of octadecanoic acid increased to $36.1 \mathrm{wt} \%$, and heptadecane was formed with a yield of. $9.2 \mathrm{wt} \%$.

Yeh et al. [47] investigated the decarboxylation of stearic, oleic, and linoleic acids with PtSnx/C catalysts at $623 \mathrm{~K}$ for two hours. The ratio of fatty acid/water ratio was $108 \mathrm{lmol}: 1.00 \mathrm{~g}$, and the ratio of catalyst/water was $5.4 \mathrm{mg}: 1.00 \mathrm{~g}$. When oleic and linoleic acids were the reactants, the $\mathrm{Pt} / \mathrm{C}$ was 
not effective to generate decarboxylation products since their yields were $16 \%$ and $18 \%$, respectively. When treating stearic acid, the yield of products formed through decarboxylation was about $70 \%$. Consequently, they realized that increasing the degrees of unsaturation decreases catalyst activity and selectivity of decarboxylation products. Besides this, they found that the addition of $\mathrm{Sn}$ in $\mathrm{Pt}$ catalysts reduced the activity of the catalyst, but this factor was compensated by the greater selectivity to heptadecane.

Zhang et al. [36] analyzed the deoxygenation of oleic acid $(0.176 \mathrm{mmol})$ at $603,623,643$, and $663 \mathrm{~K}$, for $4 \mathrm{~h}$, with $30 \mathrm{mg}$ of $30 \%$ of $\mathrm{Ni} / \mathrm{AC}$. No hydrogen and solvents were introduced in the reactions. The conversion of octadec-9-enoic acid was complete at all temperatures. They showed that the total yield of $\mathrm{C}_{17}$ and aromatics increased from $21.8 \%$ to $48.9 \%$ when the temperature raised from 603 to $643 \mathrm{~K}$ and reduced to $31.4 \%$ at $663 \mathrm{~K}$. Cracking products were less-formed at $623 \mathrm{~K}$ than at $643 \mathrm{~K}$. In addition, the total yields of $\mathrm{C}_{17}$ and aromatics increased from $44.8 \%$ to $54.5 \%$ when the catalyst loading of $\mathrm{Ni} / \mathrm{AC}$ increased from 30 to $70 \mathrm{mg}$.

Vardon et al. [14] investigated the utilization of Pt-Re/C for hydrogenation and deoxygenation of octadec-9-enoic acid with the formation of hydrogen in situ from glycerol. Moreover, $0.5 \mathrm{~g} \mathrm{Pt} / \mathrm{C}$ and $\mathrm{Pt}-\mathrm{Re} / \mathrm{C}$ were tested with $20 \mathrm{mg}$ of oleic acid at a reaction temperature of $573 \mathrm{~K}, 8-11 \mathrm{MPa}$, with $80 \mathrm{~g}$ of water, and for $9 \mathrm{~h}$. The $\mathrm{N}_{2}$ gas $(0.35 \mathrm{MPa} / 56 \mathrm{mmol})$ was initially introduced in the headspace of the reactor. Without glycerol, the octadec-9-enoic acid was only partially hydrogenated to octadecanoic acid with $\mathrm{Pt} / \mathrm{C}(31 \%)$. When $5 \mathrm{~g} / 54 \mathrm{mmol}$ of glycerol was used with $\mathrm{Pt} / \mathrm{C}$, complete hydrogenation of the octadec-9-enoic acid was observed, and incomplete deoxygenation of stearic acid occurred $(24 \%$ molar yield), generating $C_{17}$ with high selectivity ( $>98 \%$ ). Using Pt-Re/C with the addition of glycerol, $92 \%$ of octadec-9-enoic acid was hydrogenated, and $37 \%$ of stearic acid was deoxygenated. Finally, they found complete hydrogenation and deoxygenation within $2 \mathrm{~h}$, using the ratio of glycerol/fatty acid of 1:3, $2 \mathrm{~g}$ of Pt-Re/C, $573 \mathrm{~K}$, and $80 \mathrm{~g}$ of water.

Concerning the main product in the hydrothermal studies of fatty acids, most of the process focuses on the formation of heptadecane $[14,34,47]$. Even so, there are studies with the formation of other hydrocarbons or compounds. As an example, Fu et al. [48] converted $0.195 \mathrm{mmol}$ of hexadecanoic and octadec-9-enoic acids by using $5 \%$ of $\mathrm{Pt} / \mathrm{C}$ and $5 \%$ of $\mathrm{Pd} / \mathrm{C}, 0.25-0.72 \mathrm{~cm}^{3}$ of water at $643 \mathrm{~K}$, for $3 \mathrm{~h}$. For oleic acid, the major product was stearic acid, with a yield of $24 \%$, and the yield of $n$-alkanes $\left(\mathrm{C}_{12}-\mathrm{C}_{17}\right)$ and alkenes (some $\mathrm{C}_{17}$-olefins) was $10.5 \%$. For hexadecanoic acid, the main product of the hydrothermal reaction was always $\mathrm{C}_{15}$, and it was formed after three hours and $643 \mathrm{~K}$. The conversion of hexadecanoic acid was $20-24 \%$, the molar yield of $C_{15}$ was $9-10 \%$, and the selectivity of $C_{15}$ was around $40-50 \%$. Furthermore, they calculated pseudo-first-order rate constant from the hexadecanoic acid conversion measured at each of the different catalyst loadings (5-100 $\mathrm{mg} \mathrm{Pt} / \mathrm{C}$ ) and noted that pseudo-first-order rate constant increased linearly with the catalyst loading, indicating that the reaction is first-order at $643 \mathrm{~K}$, three hours, and $0.195 \mathrm{mmol}$ of palmitic acid.

Knez et al. [20] commented that the decomposition of stearic acid resulted in two main products, $\mathrm{C}_{17} \mathrm{H}_{36}$ and $\mathrm{C}_{16} \mathrm{H}_{32}$. Besides this, they noted there are catalytic effects on the surfaces of the reactor wall, particularly stainless steel, which should be considered as the main factor influencing the reaction of decarboxylation for the formation of hydrocarbons.

Miao et al. [49] studied hydrothermal deoxygenation to produce hydrocarbon from stearic acid, oleic acid, and bio-oil and with in situ production of hydrogen. In total, $500 \mathrm{mg}$ of fatty acid and $350 \mathrm{mg}$ of catalyst (the ratio of catalyst/substrate was $70 \%)$, with $4.5 \mathrm{~mL}$ of water $\left(\mathrm{H}_{2} \mathrm{O} /\right.$ fatty acids mass ratios of $0,0.5,4,9$, and 14), were loaded into the reactor. The hydrothermal deoxygenation occurred at 573 or $593 \mathrm{~K}$ and with a residence time of $6 \mathrm{~h}$. The conversion of $0.5 \mathrm{~g}$ of stearic acid at $573 \mathrm{~K}$, after $6 \mathrm{~h}$, with $0.2 \mathrm{~g}$ of catalyst loading, with $4.5 \mathrm{~mL}$ of water, and with $5 \% \mathrm{ZrO}_{2}, 5 \% \mathrm{Ni} / \mathrm{ZrO} \mathrm{O}_{2}, 10 \%$ $\mathrm{Ni} / \mathrm{ZrO}_{2}, 20 \% \mathrm{Ni} / \mathrm{ZrO}_{2}$, and $5 \% \mathrm{Pd} / \mathrm{C}$ were $7.86 \%, 27.65 \%, 59.30 \%, 67.80 \%$, and $35.21 \%$, respectively. Their corresponding paraffin yield were $0.07 \%, 18.55 \%, 28.17 \%, 43.63 \%$, and $34.54 \%$, respectively. Their corresponding selectivities to $\mathrm{C}_{8}-\mathrm{C}_{16}$ were $0 \%, 38.61 \%, 38.08 \%, 44.57 \%$, and $0.5 \%$, respectively. Moreover, their corresponding selectivities to heptadecane were $0.84 \%, 27.55 \%, 18.87 \%, 19.91 \%$, 
and $96.96 \%$, respectively. For oleic acid, approximately $78 \%$ of stearic acid was generated with $17 \%$ of paraffin yield and after $2 \mathrm{~h}$, at $673 \mathrm{~K}, 20 \%$ of $\mathrm{Ni} / \mathrm{ZrO}_{2}$, and 0.2 of water, while $28 \%$ of stearic acid was produced with $42 \%$ of paraffin yield and after $6 \mathrm{~h}$. After $6 \mathrm{~h}$, oleic acid and stearic acid reached similar yields of paraffin. The increase of reaction time from 2 to $6 \mathrm{~h}$ also increased the fraction of $\mathrm{C}_{8}-\mathrm{C}_{16} /$ total paraffin from $23 \%$ to $56 \%$. They also investigated hydrothermal deoxygenation of bio-oil from yeast Cryptococcus curvatus with different temperatures and times. The conversion of bio-oil increased from $55.39 \%$ to $100 \%$ when the temperature increased from 573 to at $593 \mathrm{~K}$, and it maintained $100 \%$ at $613 \mathrm{~K}$. The yield of paraffin increased from $31.33 \%$ to $55.17 \%$ with the increase of temperature from at 573 to $593 \mathrm{~K}$, and then it was reduced to $49.40 \%$ at $613 \mathrm{~K}$. Short-chain n-paraffin yield increased from $0.98 \%$ to $2.73 \%$ when the temperature ranged from 573 to $593 \mathrm{~K}$. At $593 \mathrm{~K}$, as the reaction time increased from 1 to $6 \mathrm{~h}$, the conversion of bio-oil and the yield of paraffin increased from $44.79 \%$ to $100 \%$ and from $20.55 \%$ to $55.17 \%$, respectively.

Kim et al. [50] studied the hydrothermal conversion of waste lipids (waste soybean oil and animal fat residuals) to liquid hydrocarbons without the necessity for adding chemical inputs such as hydrogen and methanol. For hydrothermal conversion, they used $20 \mathrm{~g}$ waste soybean oil, $2 \mathrm{~g} \mathrm{Pt}-\mathrm{Re} / \mathrm{C}$, and $80 \mathrm{~g}$ of water at $573 \mathrm{~K}$ (at a rate of $10{ }^{\circ} \mathrm{C} \mathrm{min}-1$ ) and $10 \mathrm{MPa}$. The reactor was sealed and pressurized with $\mathrm{N}_{2}(\mathrm{~g})$. For waste soybean oil, after $2 \mathrm{~h}$ of reaction, $62.8 \%$ of the fatty acids were transformed into hydrocarbons $\left(C_{15}-C_{22}\right)$, while for $4 \mathrm{~h}$, the conversion of fatty acid increased to $95 \%$, and the conversion of $100 \%$ was detected after $6 \mathrm{~h}$. They showed with gas chromatography that the initial prevalence of palmitic and stearic acids was substituted by heptadecane and pentadecane, respectively, with only small quantities of octadecane, hexadecane, and $\mathrm{C}_{19}-\mathrm{C}_{22}$ hydrocarbons. For animal fat and six hours of reaction, a complete conversion to hydrocarbons was also observed.

Edeh, Overton, and Bowra [51] investigated the hydrothermal decarboxylation of hexadecanoic acid and octadec-9-enoic acid to form pentadecane $\left(C_{15}\right)$ and heptadecane $\left(C_{17}\right)$. In total, $100 \mathrm{mg}$ of fatty acid with $20 \mathrm{mg}$ of $\mathrm{Pt} / \mathrm{C}$ and $15 \mathrm{~mL}$ of water were charged into the reactor. Temperatures of 563,573 , and $603 \mathrm{~K}$ were evaluated for the residence time of $4 \mathrm{~h}$. Different residence times $(0.5,1,1.5$, and $3 \mathrm{~h}$ for hexadecanoic acid, and $0.5,1$, and $4 \mathrm{~h}$ for octadec-9-enoic acid) were analyzed at $563 \mathrm{~K}$. For hexadecanoic acid, the maximum molar yields of $\mathrm{C}_{15}$ was $20 \%$ (at $573 \mathrm{~K}$ and $4 \mathrm{~h}$ ) and the minimum was $17.32 \%$ (at $603 \mathrm{~K}$ and $4 \mathrm{~h}$ ), and those for $\mathrm{C}_{17}$ were $5.3 \%$ ( $563 \mathrm{~K}$ and $4 \mathrm{~h}$ ) and $3.1 \%(603 \mathrm{~K}$ and $4 \mathrm{~h}$ ), respectively. The conversion of hexadecanoic acid raised from $63.4 \%$ (at $563 \mathrm{~K}$ and $4 \mathrm{~h}$ ) to $64.2 \%$ (at $573 \mathrm{~K}$ and $4 \mathrm{~h}$ ) and then decreased to $36.5 \%$ at $603 \mathrm{~K}$, while the selectivity of $\mathrm{C}_{15}$ growth from $29.2 \%$ (at $563 \mathrm{~K}$ and $4 \mathrm{~h}$ ) to $46.8 \%$ (at $603 \mathrm{~K}$ and $4 \mathrm{~h}$ ). For $\mathrm{C}_{17}$, the highest selectivity was $8.1 \%$ (at 563 and $4 \mathrm{~h}$ ) and the lowest selectivity was $5.4 \%$ (at $603 \mathrm{~K}$ and $4 \mathrm{~h}$ ). The study of the effect of reaction time using hexadecanoic acid as feedstock demonstrated that the lowest conversion was $48.7 \%$ (after $0.5 \mathrm{~h}$ ) and the highest was $79.1 \%$ (after $3 \mathrm{~h}$ ). The yield of $\mathrm{C}_{15}$ growth from $24.8 \%$ to $55.3 \%$ when the reaction time ranged from 0.5 to $1.5 \mathrm{~h}$, and then decreased to $27.6 \%$ after $3 \mathrm{~h}$. The yield of $\mathrm{C}_{17}$ increased from $1.7 \%$ to $4.4 \%$ when the reaction time increased from at 0.5 to $1.5 \mathrm{~h}$, and reduced to $3.1 \%$ after $3 \mathrm{~h}$. The maximum selectivity of $C_{15}$ was $89.1 \%$ after $1.5 \mathrm{~h}$, and the lowest selectivity of $C_{15}$ was $36.2 \%$ after $3 \mathrm{~h}$, while those of $\mathrm{C}_{17}$ were $7.3 \%$ after $1.5 \mathrm{~h}$ and $3.1 \%$ after $0.5 \mathrm{~h}$. For octadec-9-enoic acid, the influence of temperature showed that the highest and lowest conversions were $92 \%$ ( $603 \mathrm{~K}$ and $4 \mathrm{~h}$ ) and $79.9 \%$ (563 $\mathrm{K}$ and $4 \mathrm{~h}$ ). The highest molar yield of $\mathrm{C}_{15}$ was $3.6 \%$ (at $563 \mathrm{~K}$ and $4 \mathrm{~h}$ ), and the lowest molar yield of $C_{15}$ was $3.1 \%$ (603 K and $4 \mathrm{~h}$ ), and those of $C_{17}$ were $16.4 \%$ (at $563 \mathrm{~K}$ and $4 \mathrm{~h}$ ) and $10.7 \%(603 \mathrm{~K}$ and $4 \mathrm{~h}$ ). The maximum selectivity for $\mathrm{C}_{15}$ was $10.5 \%$ (at $603 \mathrm{~K}$ and $4 \mathrm{~h}$ ), and the minimum selectivity for $\mathrm{C}_{15}$ was $4.0 \%$ (and $573 \mathrm{~K}$ and $4 \mathrm{~h}$ ), and those of $C_{17}$ were $20.2 \%$ (563 $\mathrm{k}$ and $4 \mathrm{~h}$ ) and $3.2 \%(603 \mathrm{~K}$ and $4 \mathrm{~h}$ ). The influence of reaction demonstrated the lowest conversion of octadec-9-enoic acid was $53.5 \%$ after $0.5 \mathrm{~h}$, and the highest was $64.9 \%$ after $1 \mathrm{~h}$. After $1 \mathrm{~h}$, the maximum molar yield of $C_{15}$ was $4.6 \%$, and the maximum molar yield of $C_{17}$ was $7.2 \%$. The minimum values of molar yield of $C_{15}$ and $C_{17}$ were $4.0 \%$ and $4.5 \%$, and both were formed after $0.5 \mathrm{~h}$. Finally, the maximum selectivity of $\mathrm{C}_{15}$ was $7.6 \%$ after $0.5 \mathrm{~h}$ and the maximum selectivity of $\mathrm{C}_{17}$ was $11.0 \%$ after $1 \mathrm{~h}$. The minimum values were $7.0 \%$ after $1 \mathrm{~h}$ and $8.4 \%$ after $0.5 \mathrm{~h}$. 
Hossain et al. [52] studied the catalytic hydrothermal method for the decarboxylation of oleic acid with activated carbon. They used a temperature range from 623 to $673 \mathrm{~K}$, the ratio of water/oleic acid ranged from 2:1 to $4: 1, v / v$, the ratio of catalyst/oleic acid ranged from 0.15 to 0.75 , and residence times were 1 and $2 \mathrm{~h}$. They also did a blank experiment (without catalyst) with water. The conversion of oleic acid at $673 \mathrm{~K}, 2 \mathrm{~h}$, and using the ratio of oleic acid/water equal to $1: 4$ and without catalyst was $61 \%$, and the selectivity of heptadecene and heptadecane was $46 \%$ and $9 \%$, respectively. The conversion of oleic acid with $5 \mathrm{~g}$ of carbon activated catalyst for the same operating conditions was $97 \%$, and the selectivity of heptadecane, heptadecene, hexadecane, pentadecane, tetradecane, tridecane, and dodecane was $81 \%, 0.6 \%, 4 \%, 4.4 \%, 2.8 \%, 5.1 \%$, and $2.2 \%$, respectively. They also demonstrated a pseudo-first-order reaction rate that follows an Arrhenius kinetics, with an activation energy of $90.6 \pm 3 \mathrm{~kJ} \mathrm{~mol}^{-1}$. The decarboxylation kinetics of oleic acid using activated carbon as a hydrothermal catalyst was investigated at different temperatures (from $350{ }^{\circ} \mathrm{C}$ to $400^{\circ} \mathrm{C}$ ), different reaction times (from 0.5 to $2.0 \mathrm{~h}$ ), the pressure of $15.1 \mathrm{MPa}$, the ratio of water/oleic acid was 4:1 (v/v), and $5 \mathrm{~g}$ of activated carbon catalyst for each reaction.

\subsubsection{Reactions Present in Hydrothermal Technologies with Vegetable Oils and Fatty Acids}

Some authors of hydrothermal processes of fatty acids and vegetable oils have described studies focusing on possible reactions in hydrothermal technology near the supercritical region of water. The main reactions that convert fatty acids into hydrocarbons are deoxygenation reactions. Deoxygenation reactions are divided into decarboxylation, decarbonylation, and hydrodeoxygenation reactions. Decarboxylation or decarbonylation reactions generate $C_{(n-1)}$ hydrocarbons, and the hydrodeoxygenation reaction produces hydrocarbons with a $\mathrm{C}_{\mathrm{n}}+\mathrm{nH}_{2} \mathrm{O}$ carbon chain. Decarboxylation does not need the existence of hydrogen and forms $\mathrm{CO}_{2}$, while decarbonylation needs a hydrogen molecule for a fatty acid molecule and produces $\mathrm{CO}$ and $\mathrm{H}_{2} \mathrm{O}$. In addition to the main reactions, there are also side reactions in the hydrothermal medium, such as isomerization, hydrolysis, hydrogenation, ketonization, and water-gas shift reactions, dehydrogenation, methanation, catalytic, and thermal cracking.

Holliday, King, and List [23] observed the presence of geometric isomerization of linolenic acid at temperatures near $523 \mathrm{~K}$, with $0.7 \mathrm{~g} \mathrm{~mL}^{-1}$ of water and without a catalyst. However, when they observed the reactions at higher temperatures near $646 \mathrm{~K}$, they perceived decomposition and polymerization reactions of the triglycerides and fatty acids such as hexanoic, octanoic, decanoic, dodecanoic, tetradecanoic, hexadecanoic, octadecanoic, octadec-9-enoic, and octadeca-9,12-dienoic acids, which produces greases.

Hossain et al. [27] found that the $10 \mathrm{wt} \%$ of Mo-Al2O3 promotes the hydrogenation of oleic acid $(C=C$ to $C-C)$ without the addition of hydrogen and under several temperatures $(598,623,648$, and $673 \mathrm{~K})$, different ratios $(v / v)$ of water/oleic acid (5:1, 4:1, 3:1, and 2:1), and residence times $(4,2$, 1 , and $0.5 \mathrm{~h}$ ). Shin et al. [53] visualized that as the temperature increased (573-643 K), geometric or positional isomerization, hydrogenation, and cracking of fatty acid were identified. The reaction system consisted of $2 \mathrm{~mL}$ of fatty acids (octadecanoic, octadec-9-enoic, and octadeca-9,12-dienoic acids), different times (from 0 to $30 \mathrm{~min}$ ) and constant pressure (20 MPa). No catalyst was used. Moreover, they recommended that hydrolysis of triglycerides under subcritical water should be performed with temperature inferior to $573 \mathrm{~K}(20 \mathrm{MPa})$ and lower than $30 \mathrm{~min}$ to acquire high-efficiency fatty acid production.

Miao et al. [35] noted the presence of ketonization reactions. Hydrothermal catalytic deoxygenation of $0.5 \mathrm{~g}$ of palmitic acid with $0.5 \mathrm{~g}$ of $\mathrm{ZrO}_{2}$ at $573 \mathrm{~K}$, six hours, and $4.5 \mathrm{~mL}$ of water obtained palmitone selectivity equal to $51 \% \mathrm{C}$; however, in this case, $100 \mathrm{psi} \mathrm{H}_{2}$ was introduced. Moreover, $\mathrm{C}_{8}-\mathrm{C}_{14}$ varieties were produced by hydrogenolysis which also formed a significant amount of methane. The results demonstrated that hydrogenolysis and decarbonylation were the main reactions that occurred.

Nanda et al. [31] noted that high temperatures (648-948 K) favor the dehydrogenation and the water-gas shift reaction of saturated fatty acids and hydrocarbons with higher hydrogen yield. For this, 
different temperatures (648-948 K), concentrations ranging from $25 \mathrm{wt} \%$ to $40 \mathrm{wt} \%$, and different reaction times (15-60 $\mathrm{min}$ ) were applied. High amounts of raw material prioritize methanation reaction and higher amounts of methane. In addition, the catalytic study at $948 \mathrm{~K}, 25 \mathrm{wt} \%$ of waste soybean oil, and $60 \mathrm{~min}$ revealed that $5 \mathrm{wt} \%$ of $\mathrm{Ru} / \mathrm{Al}_{2} \mathrm{O}_{3}$ demonstrated maximum yield of hydrogen $(10.16 \mathrm{~mol}$ $\mathrm{kg}^{-1}$ ) due to water-gas shift reaction, whereas $5 \mathrm{wt} \% \mathrm{Ni} / \mathrm{Si}^{-} \mathrm{Al}_{2} \mathrm{O}_{3}$ resulted in high yield of methane $\left(8.15 \mathrm{~mol} \mathrm{~kg}^{-1}\right)$ due to hydrogenation and methanation reactions. They also proved that the ionic mechanism (close to $22.1 \mathrm{MPa}$ and temperature $<673 \mathrm{~K}$ ) and the free radical mechanism (temperature $>673 \mathrm{~K}$ ) prevail in the supercritical system.

The hydrothermal hydrolysis reaction in the organic phase is a first-order reaction, according to Peterson et al. [5]. Some authors have proven the order of the hydrolysis reaction in hydrothermal technology. For example, Khuwijitjaru et al. [41] observed that the hydrolysis of each ester followed first-order kinetics in the temperature range of $483-543 \mathrm{~K}$. Besides this, they noted that the methyl laurate was hydrolyzed faster than butyl laurate at $483,503,523$, and $543 \mathrm{~K}$.

Kim et al. [50] reported that decarboxylation and decarbonylation of stearic acid were the predominant in the hydrothermal deoxygenation, using $2 \mathrm{~g}$ of Pt-Re/C at $573 \mathrm{~K}, 10 \mathrm{MPa}$, and $80 \mathrm{~g}$ of water.

Finally, according to several authors, it is possible to describe a viable integrated reaction scheme for hydrothermal technology (Scheme 3). Two reaction mechanisms are predominant within the supercritical regime, being particularly the ionic mechanism and the free-radical mechanism. With the temperature near $647 \mathrm{~K}$, it is possible to observe the water acting in the hydrolysis reactions (an ionic mechanism) occasioning dehydration and cleavage of the substances. At temperatures above $647 \mathrm{~K}$, the free-radical mechanism can act on the decomposition, depolymerization, decarboxylation, and deamination reactions of the feedstock components $[5,6,18,31]$.

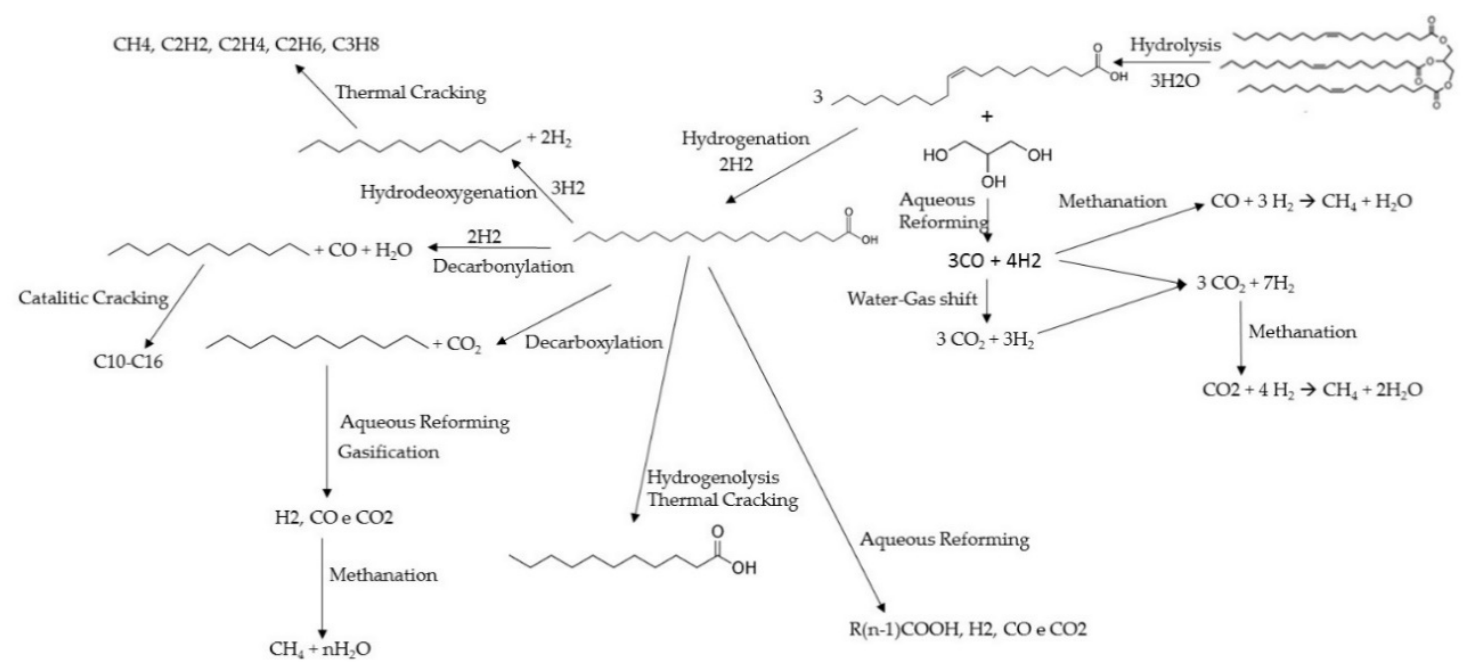

Scheme 3. Scheme of reaction for hydrothermal processing of the triacylglycerides into alkanes.

Initially, the triglyceride is hydrolyzed to fatty acid and glycerol. Glycerol released by hydrolysis may undergo water phase reforming reactions to generate $\mathrm{H}_{2}$ or may be catalytically decomposed to generate $\mathrm{CO}$, which will be subsequently consumed by the water-gas shift reaction for additional $\mathrm{H}_{2}$ generation $[14,18]$.

The hydrolysis is reversible and a first-order reaction. In the first stage, the triglyceride is hydrolyzed to diglyceride; in the second stage, the diglyceride is hydrolyzed to monoglyceride; and in the third stage, the monoglyceride is hydrolyzed to fatty acid and glycerol. In each stage, there is the formation of fatty acid [24]. The hydrolysis reaction produces diglycerides, monoglycerides, and fatty acid, which are shown in Scheme 4. 


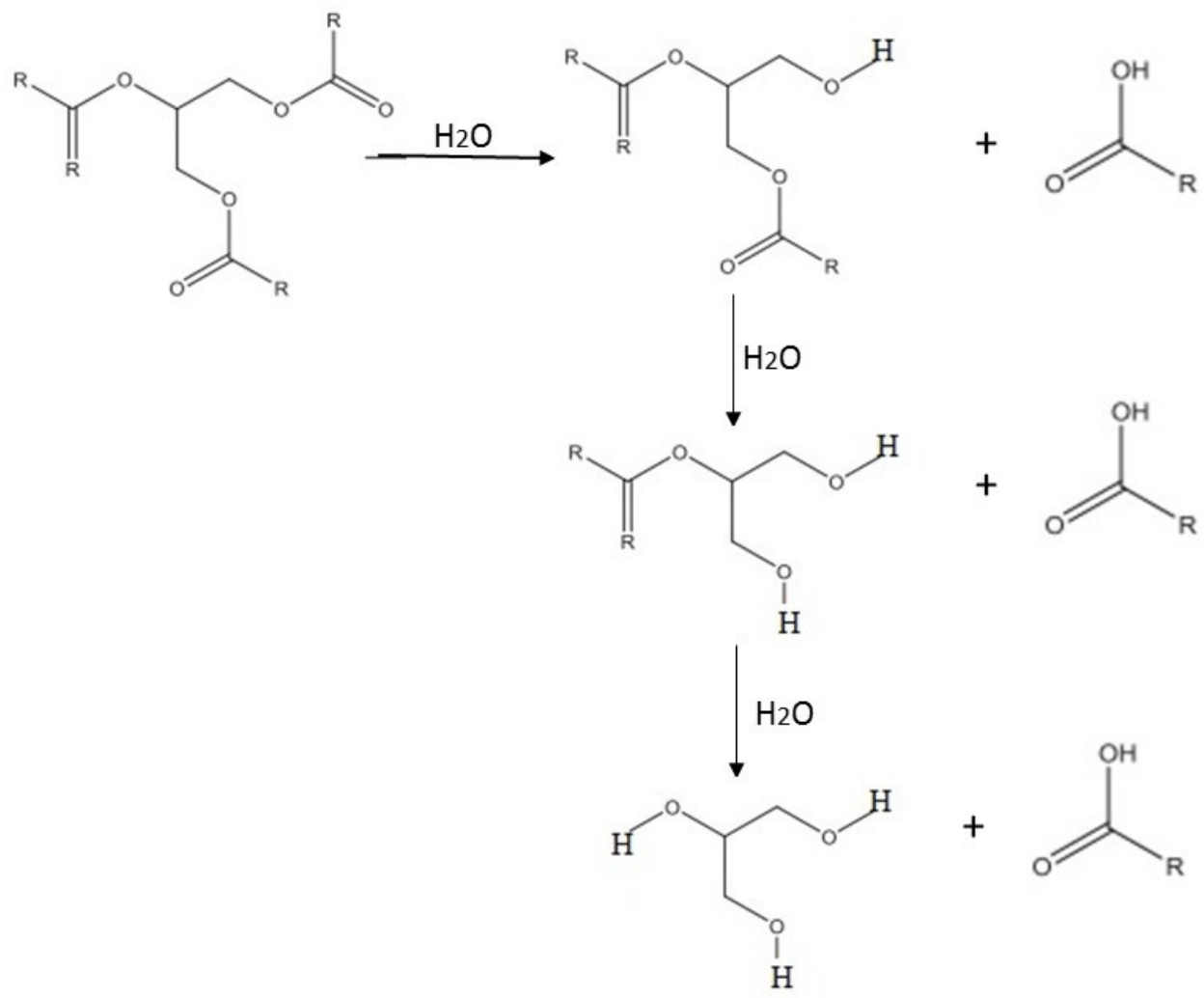

Scheme 4. Reaction sequence of the hydrolysis reaction from triglyceride.

Lipid conversion is much faster than free fatty acids because of the in-situ production of $\mathrm{H}_{2}$ through aqueous-phase reforming of the glycerol generated during the hydrolysis of triglyceride [38]. In the presence of excess glycerol, there is an increase in the hydrothermal deoxygenation activity [54]. This can be explained by the fact that each glycerol molecule can generate at least $4 \mathrm{H}_{2}$ molecules and at most $7 \mathrm{H}_{2}$ molecules. The aqueous-phase reforming of glycerol was shown in Equations (1) and (2).

$$
\begin{gathered}
\text { Glycerol } \rightarrow 3 \mathrm{CO}+4 \mathrm{H}_{2} \\
3 \mathrm{CO}+3 \mathrm{H}_{2} \mathrm{O} \rightarrow 3 \mathrm{CO}_{2}+3 \mathrm{H}_{2}
\end{gathered}
$$

Along with in situ $\mathrm{H}_{2}$ production, shorter chain fatty acid production can also occur through fatty acid thermal cracking reactions, which will depend on the optimal cracking temperature range for each fatty acid and by successive hydrogenolysis [49].

Successive hydrogenolysis occurs by cleavage of carbon-carbon bonds. The presence of methane in the gaseous products and the increase in hydrocarbons with lower carbon-chains evidenced the presence of hydrogenolysis [49]. That is, initially stearic acid is broken by cleavage of the final carbon-carbon bond to produce heptadecanoic acid. Heptadecanoic acid may be further broken down to form pentadecanoic acid or may be converted into hexadecane through decarboxylation or decarbonylation reactions. The pentadecanoic acid formed will repeat the pathway to form tetradecanoic acid or n-tetradecane.

The presence of unsaturated fatty acids undergoes hydrogenation reactions to produce saturated fatty acids. The saturated fatty acids formed may follow two pathways for the production of shorter chain alkanes. The first possibility is the fatty acid hydrogenolysis and then its deoxygenation reactions (hydrodeoxygenation, decarbonylation, and decarboxylation reactions). The second alternative is the deoxygenation of the fatty acid and then the catalytic cracking of hydrocarbons produced. In both pathways, decarboxylation and decarbonylation reactions are present, with the loss of one molecule of $\mathrm{CO}_{2}$ and $\mathrm{CO}$, respectively, which will result in the formation of aliphatic hydrocarbons having an 
equal carbon number of $C_{n-1}$. When there is not the production of new fatty acids different from the feedstock, and there is only the formation of hydrocarbons, it can be concluded that decarboxylation, decarbonylation, or hydrodeoxygenation reactions occur first and thereafter catalytic cracking [38].

Besides this, both short-chain saturated fatty acids and long-chain saturated fatty acids may undergo other reactions. These include steam reforming to produce $\mathrm{H}_{2}, \mathrm{CO}$, and $\mathrm{CO}_{2}$; thermal cracking to form $\mathrm{CH}_{4}$, acetylene $\left(\mathrm{C}_{2} \mathrm{H}_{2}\right)$, ethylene $\left(\mathrm{C}_{2} \mathrm{H}_{4}\right)$, ethane $\left(\mathrm{C}_{2} \mathrm{H}_{6}\right)$, and propane $\left(\mathrm{C}_{3} \mathrm{H}_{8}\right)$; and catalytic cracking, which will depend on the type of catalyst, to produce light hydrocarbons $\left(\mathrm{C}_{10}-\mathrm{C}_{16}\right)[18,31]$. Moreover, there are others reactions in the hydrothermal technology; for instance, methanation is favored between 373 and $673 \mathrm{~K}$ and high pressure, and it reacts the hydrogen with $\mathrm{CO}$ or $\mathrm{CO}_{2}$ to form $\mathrm{CH}_{4}$ and the gasification that becomes predominant above $647 \mathrm{~K}$ and converts hydrocarbons and short-chain fatty acids into $\mathrm{H}_{2}, \mathrm{CO}$, and $\mathrm{CO}_{2}$. Both, however, decrease the degree of deoxygenation of fatty acids in hydrothermal technology.

\subsection{Trends for Hydrothermal Experiments Using Vegetable Oils and Fatty Acids}

Figure 5 shows the number of articles published per year. The number of hydrothermal articles using fatty acids and triglycerides as raw materials is 15 and 21 articles, respectively. The oldest article was published in 1997 and studies the hydrolysis of vegetable oils, using subcritical water and without catalysts to produce fatty acids [23]. Hydrothermal processes using triglycerides as raw materials emerged in 1997. Until 2015, there was only one article published per year. In 2018 and 2019, three documents were published each year. Hydrothermal articles using fatty acids as feedstock, on the other hand, emerged in 2002. The year with the highest number of published articles was 2015, with four documents. In 2019, three documents were published. In 2020, no hydrothermal article using fatty acid or triglyceride has been published.

(a)

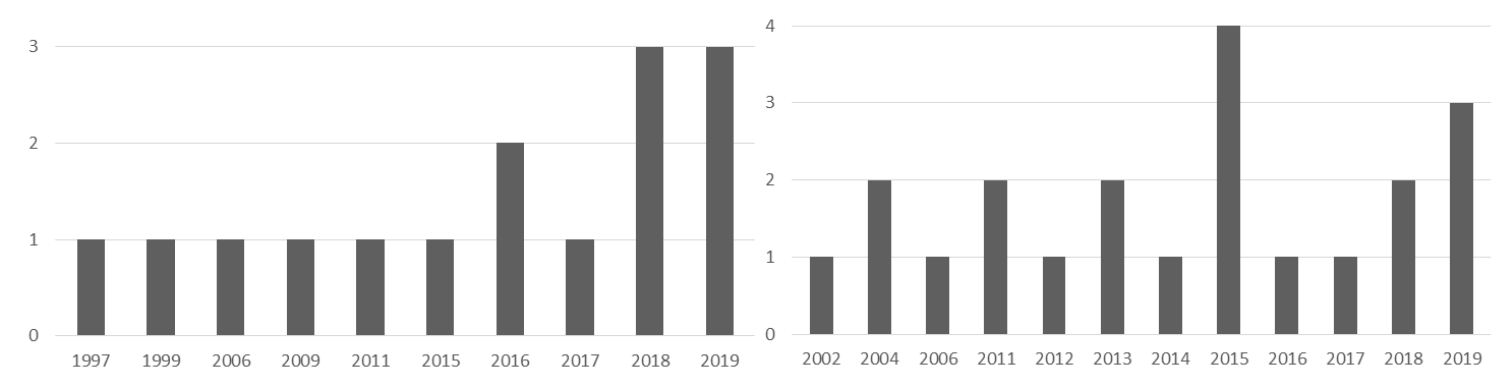

Figure 5. Timeline of published articles on hydrothermal technologies from (a) vegetable oils and (b) fatty acids.

Most of the countries that have published hydrothermal articles are in the West. The United States of America has published the largest number of hydrothermal articles, with thirteen articles (four articles use vegetable oil and nine documents use triglycerides as raw materials). Then there is China, with seven documents (two articles use vegetable oil and five documents use fatty acids as feedstock). It is interesting to comment that India, Australia, and the Netherlands published one article each.

Moreover, some articles were prepared through partnerships between universities and research centers. For hydrothermal articles from fatty acids, the partnerships that exist were between United States and China, with Zhejiang University and the University of Michigan, and with Chongqing University and the Colorado School of Mines. For hydrothermal articles from triglycerides, the partnerships that exist were between the United Kingdom and Kuwait, with the University of Birmingham and the Kuwait Institute for Scientific Research; between the Republic of Korea and the United States, with the Korean Military Academy, the National Renewable Energy Center, the Illinois Sustainable Technology Center, and the Colorado School of Mines; and between Canada and China, with the University of Western Ontario, the University of Saskatchewan, Saskatoon, York University, 
the Nanjing Agricultural University, and the University of Waterloo. Figure 6 shows the number of articles published for each country.

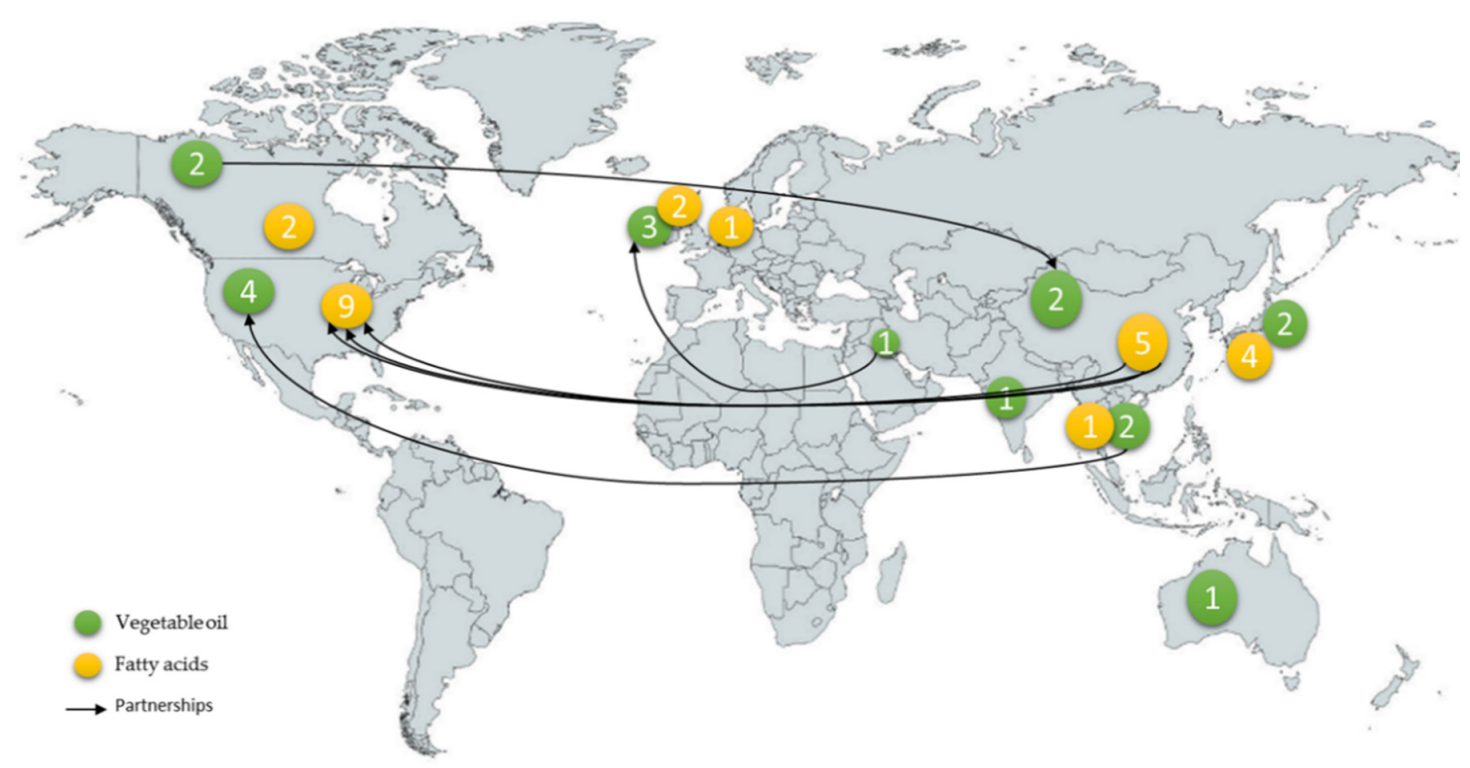

Figure 6. Number of articles published per each country.

Regarding hydrothermal technology, from the current stage to the short-term, it is possible to observe a greater emphasis on the "process". The main trends observed over time are the identification of catalysts that favor deoxygenation reactions from fatty acids to hydrocarbons and studies of the hydrothermal process with in situ hydrogen production. Moreover, the identification of the compounds obtained and the elucidation of the main reactions that occur in the hydrothermal process are considered important trends.

The parameters of the process most studied over time are reactor temperature, residence time, feedstock, biomass:water ratio, and catalyst loading. In the long-term, the greatest concern will be to find the optimization of these parameters that allow greater selectivity and yields. Moreover, another concern is the use of raw materials with no added value, such as waste from the vegetable oil industry. The major trend observed for the long-term will be the search for hydrothermal processes at a temperature close to the supercritical water, aiming at producing drop-in biofuels.

As a matter of fact, the analysis of all hydrothermal experimental articles demonstrated that the majority has an interest in hydrothermal reactions that occur at a temperature close to the supercritical reaction (523-647 K and $<220$ bar). Furthermore, their main objective is to convert fatty acids and triglycerides into a liquid product with chemical properties entirely different from raw materials such as renewable hydrocarbons (paraffin, aromatics, and olefins). This preference occurs since triglycerides and fatty acids can be used as raw material to generate renewable fuel; and the catalytic decarboxylation of triglycerides is a promising route for producing hydrocarbons $[5,18,27]$. Figures 7 and 8 show the temperatures used for reactions with fatty acids and triglycerides. For triglycerides, only Chen et al. [30] and Nada et al. [31] investigated the hydrothermal technology into the supercritical region (hydrothermal gasification $\longrightarrow>647 \mathrm{~K}$ ), while for fatty acid, there were the articles of Mo, Tandar, and Savage [19]; Mo and Savage [39]; Watanabe et al. [43]; Hossain et al. [45]; and Miao et al. [49]. 


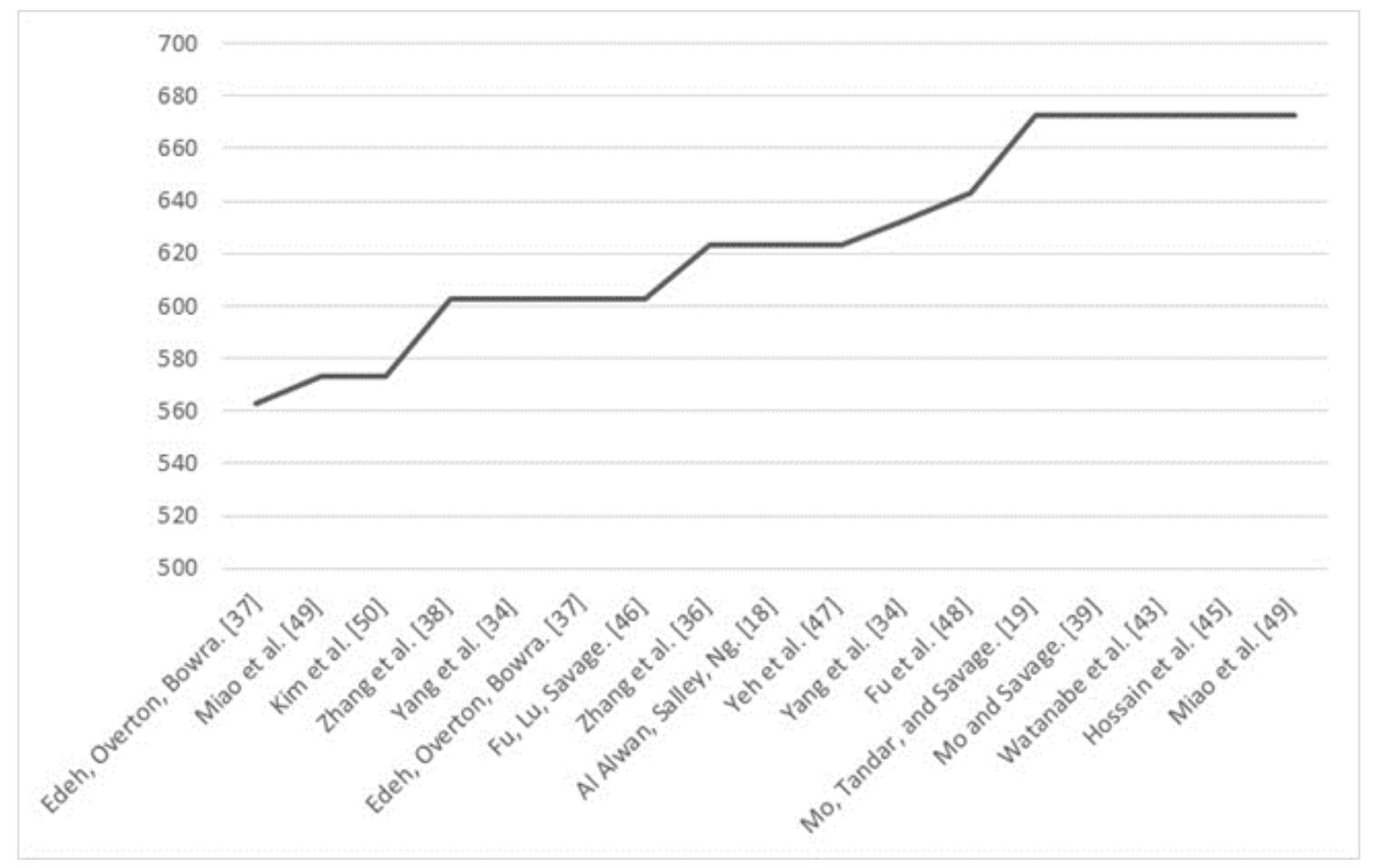

Figure 7. Temperatures (K) used in hydrothermal experiments with fatty acids.

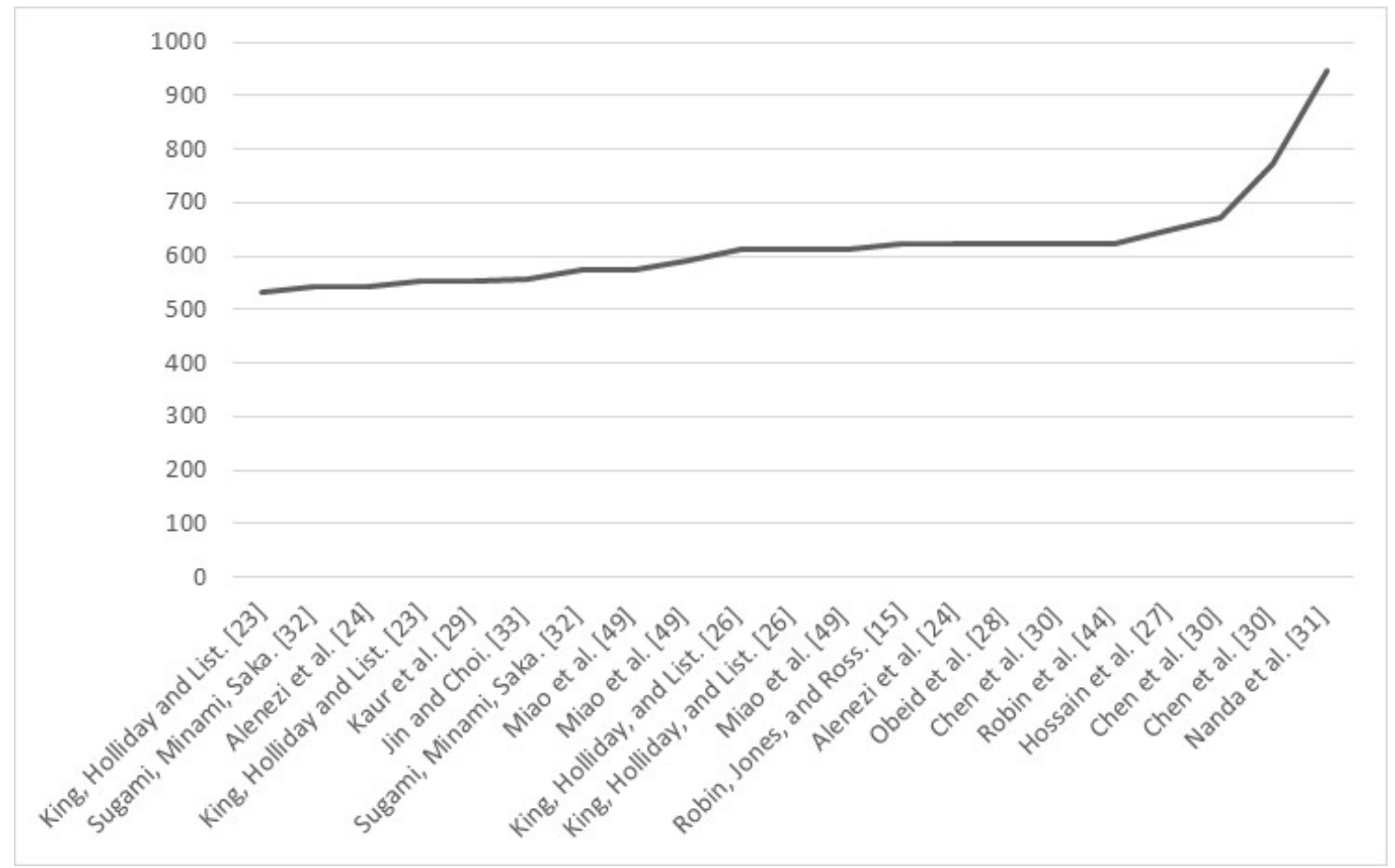

Figure 8. Temperatures $(\mathrm{K})$ used in hydrothermal experiments with triglycerides.

Concerning raw materials, most hydrothermal articles with triglycerides chose sunflower and soybean oils as feedstocks. However, it was possible to observe other vegetable oils, such as coconut, castor, rapeseed, palm, and linseed oils. This demonstrated the necessity of using other vegetable oils, especially the residue they produced after their extraction and use. The production of vegetable oil produces partially defatted residues, which are rich in vegetable fibers, proteins, and some lipids that 
can generate different products with greater added value upon hydrothermal technology. For example, Kim et al. [50] used waste soybean oil and converted 95\% to hydrocarbons $\left(C_{15}-C_{22}\right)$ after $6 \mathrm{~h}, 2 \mathrm{~g}$ $\mathrm{Pt}-\mathrm{Re} / \mathrm{C}$ at $573 \mathrm{~K}$, and $10 \mathrm{Mpa}$, while for fatty acids, most chose saturated fatty acids as model components for hydrothermal reactions. Palmitic and stearic acids were the most used. Articles by Khuwijitjaru, Adachi, and Matsuno [40] and Yang et al. [34] used other types of fatty acid, such as capric, myristic, lauric, arachidic, and behenic acids, and Khuwijitjaru et al. [41] applied fatty acid esters. It was noted, however, that unsaturated fatty acids have also been used as raw material. Most of the cases were from comparative studies between saturated and unsaturated fatty acids. The most investigated unsaturated fatty acids were oleic and linoleic acids.

Most hydrothermal articles using triglycerides as feedstock did not show conversion values. Their focus was on the yield of alkanes and fatty acids that ranged from 8 to $72 \mathrm{wt} \%$ and from $12 \%$ to $100 \%$, respectively. For studies with fatty acids, it is possible to see from Figure 9 that there is no single value for conversion. One explanation for the large discrepancy in conversion and yield values is that they are due to the different reactions that occur simultaneously from the feedstock in the subcritical and supercritical environment of water, making the hydrothermal process complex. At the same time, due to the coexistence of the liquid and gaseous phases of water, numerous side reactions coexisted. Besides, the rate of the reactor, the temperature, the reaction time, and the amount of catalyst can also influence the results of conversion, yield, and selectivity.

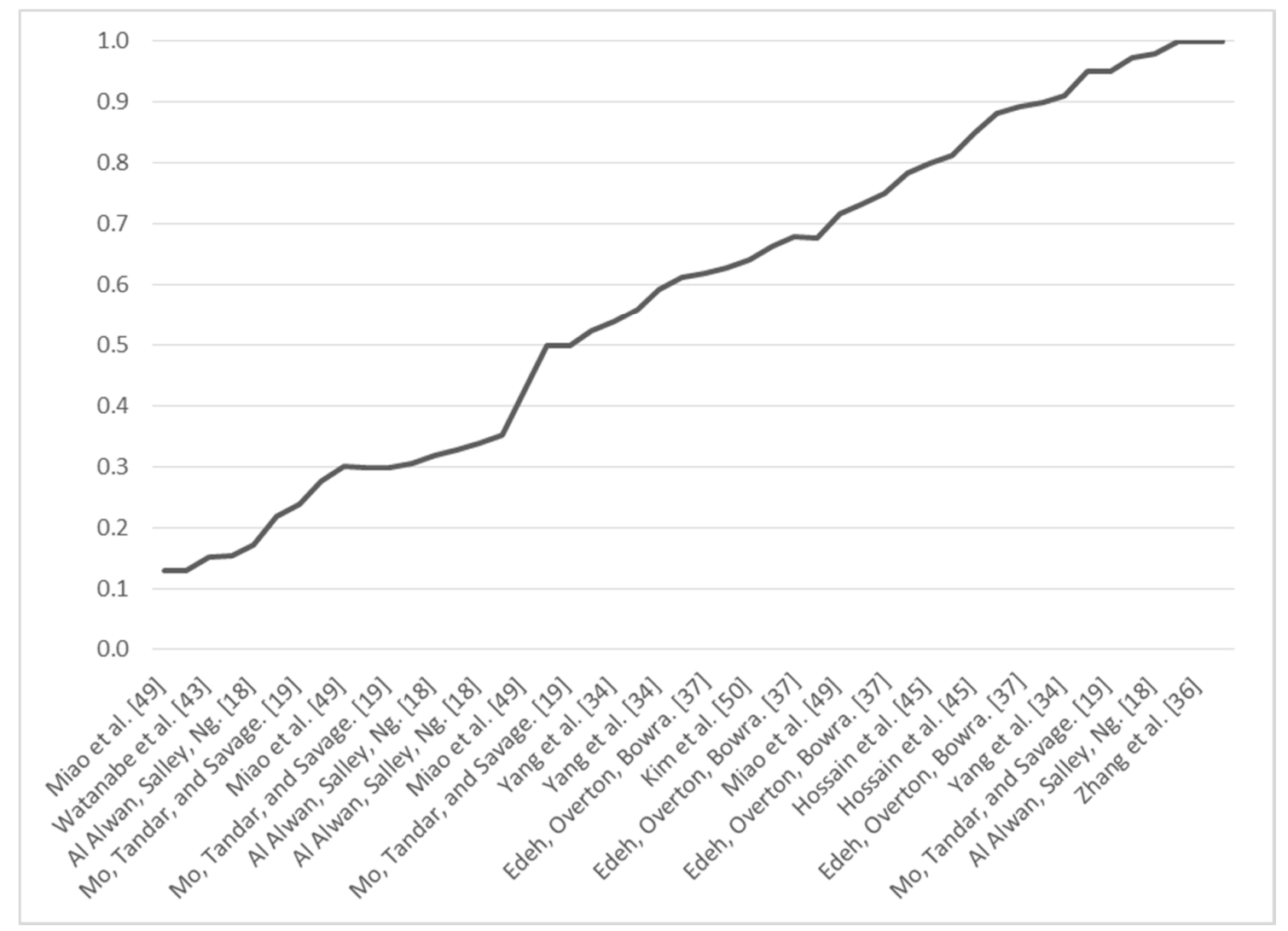

Figure 9. Conversion of fatty acids in hydrothermal experiments.

The use of catalysts in hydrothermal technology aims to develop the efficiency of the process [6]. Most of the hydrothermal articles with triglycerides and fatty acids that were analyzed preferred to use heterogeneous catalysts. Studies that applied metallic catalysts with platinum, palladium, nickel, and ruthenium were found. Catalysts containing noble metals such as $\mathrm{Pt}, \mathrm{Pd}, \mathrm{Ni}$, and $\mathrm{Ru}$ are expensive, and, for this reason, studies have shifted the focus to the use of metal oxides [6]. Among them, articles that applied metallic oxides such as $\mathrm{ZrO}_{2}$, ceria $\left(\mathrm{CeO}_{2}\right)$, and yttria $\left(\mathrm{Y}_{2} \mathrm{O}_{3}\right)$ 
were found $[43,49]$. Some articles used noble metals coupled with metal oxides, such as $\mathrm{Ni} / \mathrm{ZrO} 2$ catalysts [35,49]. Other articles also used activated carbon as a catalyst, since it is cheap, it is very effective for hydrothermal decarboxylation of fatty acids, and it contributes to the steam reforming to generate hydrogen [45]. The use of zeolites has also been observed in hydrothermal articles. Zeolite catalysts were chosen since they could catalyze reactions of cracking and aromatization, and they could convert fatty acids into aromatic substances, along with olefins and paraffins in supercritical water $[19,39]$. Among the zeolites used were zeolite $Y$, zeolite beta, ZSM-5, HZSM-5, and MoZSM-5. In addition to heterogeneous catalysts, homogeneous catalysts comprising alkali salts such as $\mathrm{NaOH}$ and $\mathrm{KOH}$ were also applied in hydrothermal processes. Alkali salts decrease the production of char/tar, as the $\mathrm{OH}$ - neutralizes the substances causing polymerization in char formation, accelerates the water-gas shift reaction, which increases the product yield, and does not undergo deactivation problems $[5,6]$. Finally, articles without the presence of catalysts were also found. Their purpose was to study the non-catalytic thermal hydrolysis and the hydrothermal technology without a catalyst.

Regarding residence time, most articles chose to work with times longer than an hour of reaction. For fatty acids, as can be seen in Figure 10, most cases chose to work between one and six hours. Zhang et al. [38] and Hossain et al. [45] used reaction times longer than six hours. Zhang et al. [38] studied catalytic hydrothermal decarboxylation and cracking, and Hossain et al. [45] investigated the thermal regeneration of activated carbon. For vegetable oils, the reaction times were shorter, ranging from 10 to $240 \mathrm{~min}$ (Figure 11).

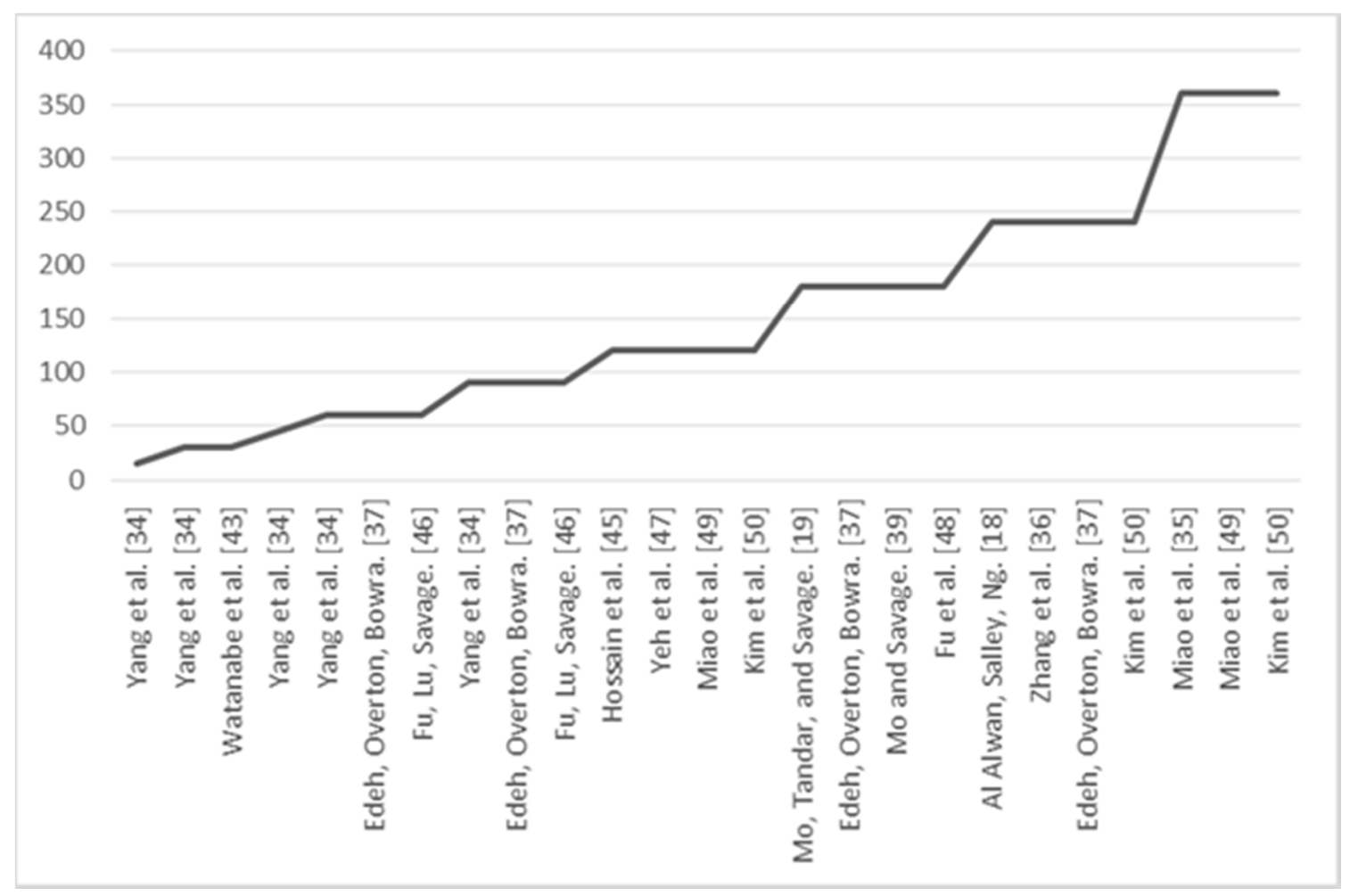

Figure 10. Residence time (minutes) in hydrothermal experiments with fatty acids. 


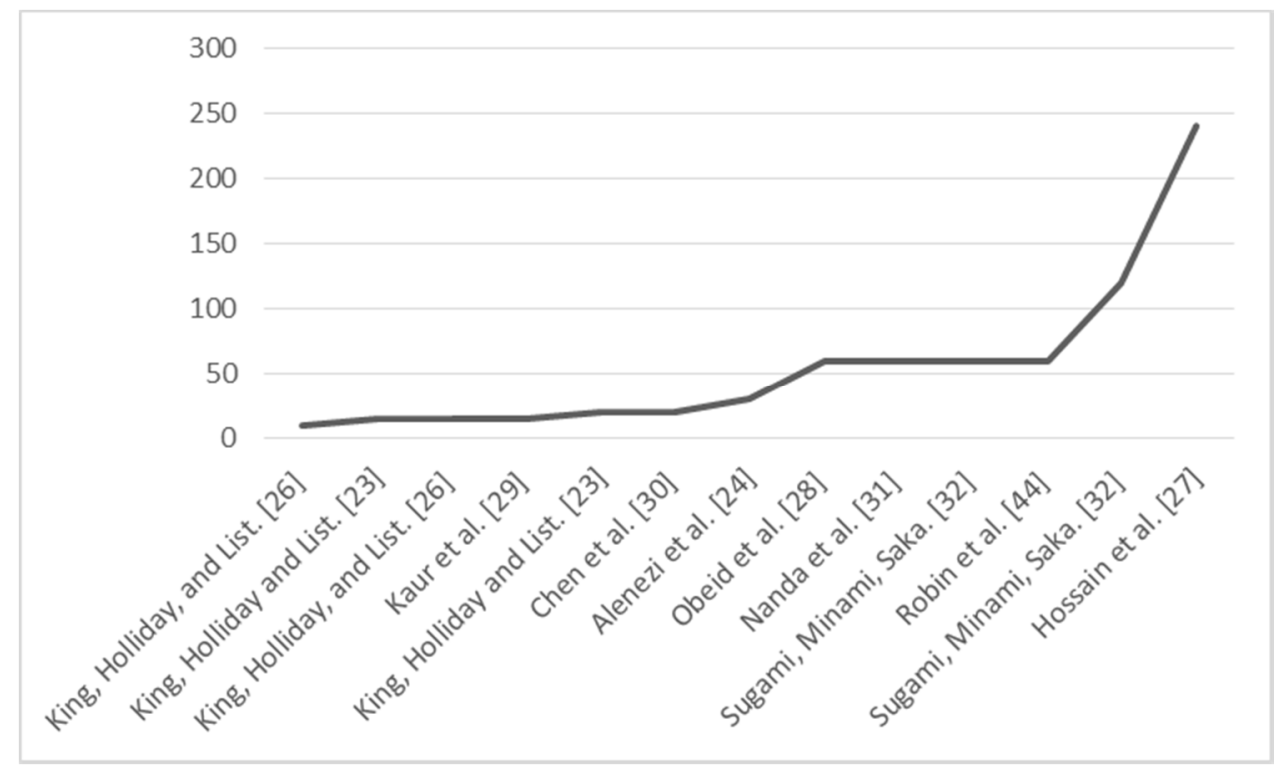

Figure 11. Residence time (minutes) in hydrothermal experiments with vegetable oil.

In most of the investigated hydrothermal articles, pressures were autogenous; in other words, they were generated by temperature during the hydrothermal process. A potential advantage that occurs with the change in temperature and pressure in the presence of sub- and supercritical water is the possibility of obtaining large variations in the properties of the reaction medium and optimizing the reaction without the need to apply a solvent [5]. For articles that controlled the pressure, for both vegetable oils and fatty acids, they operated at pressures ranging from 5 to $25 \mathrm{MPa}$ (Figures 12 and 13).

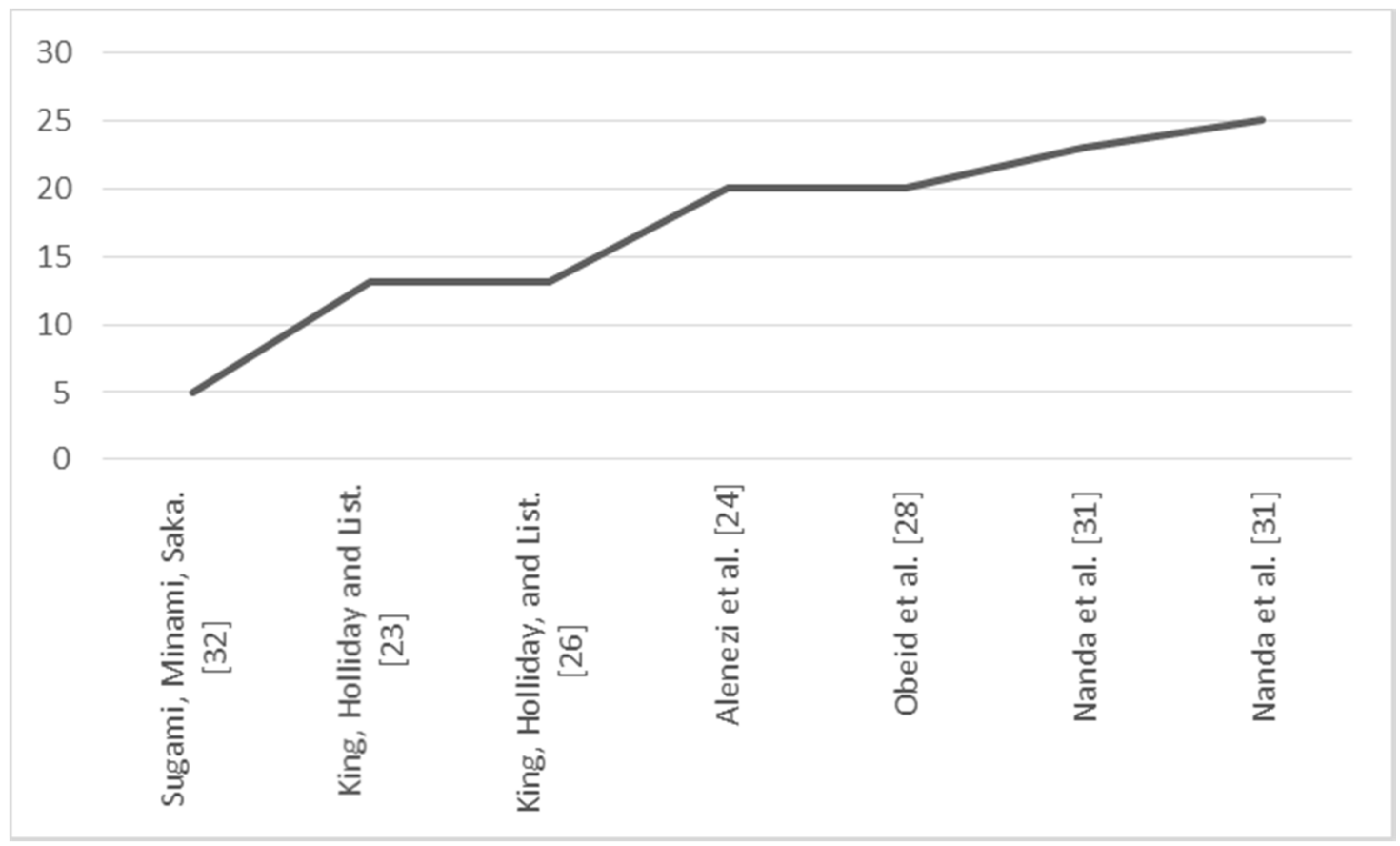

Figure 12. Pressure (MPa) in hydrothermal experiments with vegetable oils. 


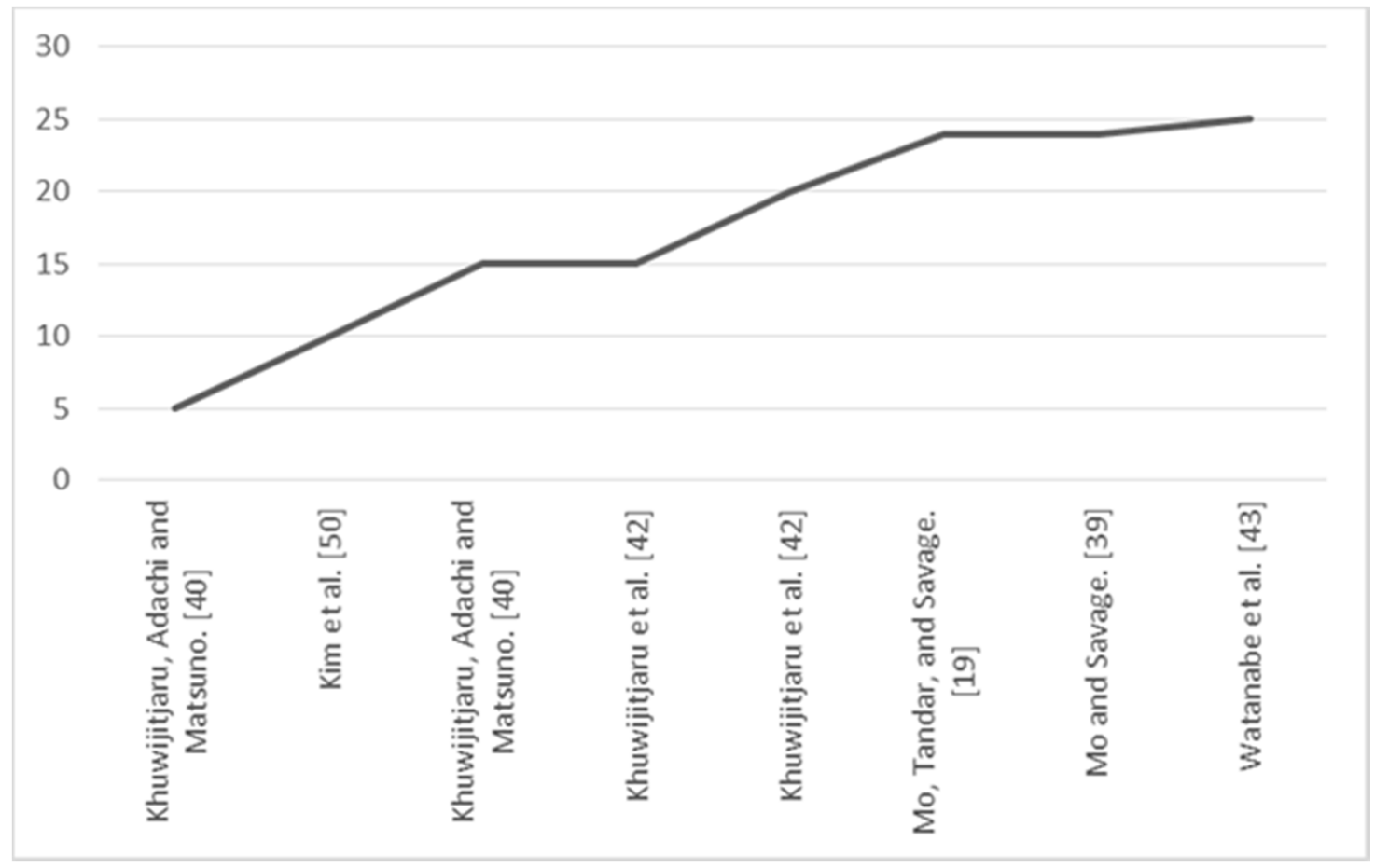

Figure 13. Pressure (MPA) in hydrothermal experiments with fatty acids.

As it can be seen from all the results exposed in this study, the hydrothermal process still needs to be continuously explored. Even though the results cover a wide range of process parameters, such parameters have not been optimized. Therefore, it is not possible to state what are the ideal conditions (temperature, pressure, amount of catalyst, water/biomass ratio, and residence time) for obtaining high conversions, along with high hydrocarbon yields and high selectivities, at the same time. Before doing the optimization of the hydrothermal process, it is important to overcome many challenges, including the following: (1) the reactors are very complex and expensive, and they have to operate with high pressures and high capacity to handle of water; (2) the comprehension of mass balance makes it difficult to exactly measure product yields during the hydrothermal reaction; (3) the formation of coke and tar; and (4) the clogging and the obstruction of the reactor caused by the precipitation of organic salts combined with coke $[6,8,9]$.

Finally, some challenges should be further explored in hydrothermal articles, including the following:

- The analysis of critical parameters (temperature, pressure, residence time, and catalyst) with the results of selectivity, yield for hydrocarbons, and conversion of the raw material; currently, most articles focus only on temperature and residence time;

- The optimization of the hydrothermal process, presenting optimal parameters such as temperature, pressure, residence time, amount of catalyst, and biomass/water ratio;

- The comparison between the results obtained with model compounds and real biomass;

- The study of the gas phase formed in the hydrothermal process, with its main products and reactions pathways;

- The investigation of the main pathways of hydrogen formation in situ (water-gas shift reaction and aqueous-phase reforming);

- The investigation of how a raw material's chemical structure influences hydrothermal reactions;

- Kinetics studies of the hydrothermal reaction, comparing results obtained with model compounds and real biomass.

- The study and analysis of the results obtained after the regeneration of various types of catalysts. 


\section{Conclusions}

In conclusion, the hydrothermal process is a recent technique. Since 2008, there has been a growth in technological studies concerning hydrothermal processes. Additionally, it is possible to see the motivation to apply hydrothermal technology in vegetable oils, to produce renewable hydrocarbons and drop-in fuels. The hydrothermal process is a promising technique to produce biofuels, because it obtains high yields, has high energy during the reaction, and has efficiency in the step of separation. Most of the hydrothermal processes that use vegetable oils and fatty acids produce only hydrocarbons in the organic phase. Most saturated fatty acids have a higher percentage of fatty acids, ranging from dodecanoic acid to eicosanoic acid. Hence, when the hydrothermal process occurs, these saturated fatty acids undergo decarboxylation, decarbonylation, and produce $C_{n-1}$ hydrocarbons similar to those present in gasoline, kerosene, or diesel $\left(C_{9}-C_{19}\right)$. Moreover, some by-products may be generated in hydrothermal technology of vegetable oils and fatty acids. They are $\mathrm{CH}_{4}$ (methanation or hydrogenolysis), $\mathrm{H}_{2}, \mathrm{CO}$ and $\mathrm{CO}_{2}$ (steam reforming), acetylene $\left(\mathrm{C}_{2} \mathrm{H}_{2}\right)$, ethylene $\left(\mathrm{C}_{2} \mathrm{H}_{4}\right)$, ethane $\left(\mathrm{C}_{2} \mathrm{H}_{6}\right)$, and propane $\left(\mathrm{C}_{3} \mathrm{H}_{8}\right)$ (thermal cracking). As aforementioned, more stringent environmental regulations call for the development of green middle distillate derivatives. Main commercial middle distillate fuels are diesel and jet fuel, whose carbon chains are in the range of $C_{9}$ to $C_{15}$. Hence, it is important to choose a raw material that allows the production of hydrocarbons between $C_{9}$ and $C_{15}$. Furthermore, one must employ process temperatures between 623 and $673 \mathrm{~K}$, a heterogeneous noble-metal-containing catalyst (such as $\mathrm{Pd}, \mathrm{Pt}$, or $\mathrm{Ni}$ ), and reaction times longer than one hour.

Author Contributions: Conceptualization, C.Z.C.; methodology, C.Z.C.; formal analysis, C.Z.C.; investigation, C.Z.C.; resources, E.F.S.-A. and M.A.P.G.C.; data curation, C.Z.C.; writing-original draft preparation, C.Z.C.; writing-review and editing, C.Z.C., E.F.S.-A., M.A.G.P.C., and J.F.S.d.C.F.; visualization, C.Z.C., E.F.S.-A., M.A.P.G.C., and J.F.S.d.C.F.; supervision, E.F.S.-A., M.A.P.G.C., and J.F.S.d.C.F.; project administration, C.Z.C. All authors have read and agreed to the published version of the manuscript.

Funding: This research received no external funding.

Acknowledgments: The authors would like to thank Coordenação de Aperfeiçoamento de Pessoal de Nível Superior (CAPES) for the fellowships.

Conflicts of Interest: The authors declare no conflict of interest.

\section{References}

1. Chiaramont, D.; Oasmaa, A.; Solantausta, Y. Power generation using fast pyrolisis liquids from biomass. Renew. Sustain. Energy Rev. 2007, 11, 1056-1086. [CrossRef]

2. Tsitaa, K.G.; Kiartzisb, S.J; Ntavosa, N.K.; Pilavachi, P.A. Next generation biofuels derived from thermal and chemical conversion of the Greek transport sector. Therm. Sci. Eng. Prog. 2020, 17, 1-7. [CrossRef]

3. Zhou, Y.; Nanda, S.; Hu, C. Catalytic thermochemical conversion of algae and upgrading of algal oil for the production of high-grade liquid fuel: A review. Catalysts 2020, 10, 145. [CrossRef]

4. Ong, H.C.; Chen, W.-H.; Farooq, A.; Gana, Y.Y.; Leed, K.T.; Ashokkumar, V. Catalytic thermochemical conversion of biomass for biofuel production: A comprehensive review. Renew. Sustain. Energy Rev. 2019, 109266. [CrossRef]

5. Perterson, A.A.; Vogel, F.; Lachance, R.P.; Fröling, M.; Antal, M.J., Jr.; Tester, J.W. Thermochemical biofuel production in hydrothermal media: A review of sub- and supercritical water technologies. Energy Environ. Sci. 2008, 1, 32-65. [CrossRef]

6. Kumar, M.; Ouedum, A.O.; Kumar, A. A review on the current status of various hydrothermal technologies on biomass feedstock. Renew. Sustain. Energy Rev. 2018, 81, 1742-1770. [CrossRef]

7. Patel, B.; Guo, M.; Izadpanah, A.; Shah, N.; Hellgardt, K. A review on hydrothermal pre-treatment technologies and environmental profiles of algal biomass processing. Bioresour. Technol. 2016, 199, 288-299. [CrossRef]

8. Toor, S.S.; Rosendahl, L.; Rudolf, A. Hydrothermal liquefaction of biomass: A review of subcritical water Technologies. Energy 2011, 36, 2328-2342. [CrossRef] 
9. Nanda, S.; Isen, J.; Dalai, A.K.; Kozinski, J.A. Gasification of fruit wastes and agro-food residues in supercritical water. Energy Convers. Manag. 2016, 110, 296-306. [CrossRef]

10. Elliott, D.C.; Biller, P.; Ross, A.B.; Schmidt, A.J.; Jones, S.B. Hydrothermal liquefaction of biomass: Developments from batch to continuous process. Bioresour. Technol. 2015, 178, 147-156. [CrossRef] [PubMed]

11. Toor, S.S.; Reddy, H.; Deng, S.; Hoffmann, J.; Spangsmark, D.; Madsen, L.B. Hydrothermal liquefaction of Spirulina and Nannochloropsis salina under subcritical and supercritical water conditions. Bioresour. Technol. 2013, 131, 413-419. [CrossRef] [PubMed]

12. Gollakota, A.R.K.; Kishore, N.; Gu, S. A review on hydrothermal liquefaction of biomass. Renew. Sustain. Energy Rev. 2018, 81, 1378-1392. [CrossRef]

13. Idesh, S.; Kudo, S.; Norinaga, K.; Hayashi, J.-I. Catalytic hydrothermal reforming of jatropha oil in subcritical water for the production of green fuels: Characteristics of reactions over Pt and Ni catalysts. Energy Fuels 2013, 27, 4796-4803. [CrossRef]

14. Vardon, R.; Sharma, B.; Jaramillo, H.; Kim, D.; Choe, J.; Ciesielski, P.; Strathmann, T. Hydrothermal catalytic processing of saturated and unsaturated fatty acids to hydrocarbons with glycerol for in situ hydrogen production. Green Chem. 2014, 16, 1507-1520. [CrossRef]

15. Robin, T.F.; Jones, J.M.; Ross, A.B. Catalytic hydrothermal processing of lipids using metal doped zeolites. Biomass Bioenergy 2017, 98, 26-36. [CrossRef]

16. Ramirez, J.A.; Brown, R.J.; Rainey, T.J. A review of hydrothermal liquefaction bio-crude properties and prospects for upgrading to transportation fuels. Energies 2015, 8, 6765-6794. [CrossRef]

17. Tzanetis, K.F.; Posada, J.A.; Ramirez, A. Analysis of biomass hydrothermal liquefaction and biocrude-oil upgrading for renewable jet fuel production: The impact of reaction conditions on production costs and GHG emissions performance. Renew. Energy 2017, 113, 1388-1398. [CrossRef]

18. Al Alwan, B.; Salley, S.O.; Ng, S.K.Y. Biofuels production from hydrothermal decarboxylation of oleic acid and soybean oil over Ni-based transition metal carbides supported on Al-SBA-15. Appl. Catal. A 2015, 498, 32-40. [CrossRef]

19. Mo, N.; Tandar, W.; Savage, P.E. Aromatics from saturated and unsaturated fatty acids via zeolite catalysis in supercritical water. J. Supercrit. Fluids 2015, 102, 73-79. [CrossRef]

20. Knez, Z.; Hrncic, M.K.; Čolnik, M.; Škerget, M. Chemicals and value added compounds from biomass using sub- and supercritical water. J. Supercrit. Fluids 2018, 133, 591-602. [CrossRef]

21. Kipçak, E.; Sögüt, O.O.; Akgun, M. Hydrothermal gasification of olive mill wastewater as a biomass source in supercritical water. J. Supercrit. Fluids 2011, 57, 50-57. [CrossRef]

22. Wang, Y.; Chen, G.; Li, Y.; Yan, B.; Pan, D. Experimental study of the bio-oil production from sewage sludge by supercritical conversion process. J. Waste Manag. 2013, 33, 2408-2415. [CrossRef] [PubMed]

23. Holliday, R.L.; King, J.W.; List, G.R. Hydrolysis of vegetable oils in sub-and supercritical water. Ind. Eng. Chem. Res. 1997, 36, 932-935. [CrossRef]

24. Alenezi, R.; Leeke, G.A.; Santos, R.C.D.; Khan, A.R. Hydrolysis kinetics of sunflower oil under subcritical water conditions. Chem. Eng. Res. Des. 2009, 87, 867-873. [CrossRef]

25. Fujii, T.; Khuwijitjaru, P.; Kimura, Y.; Adachi, S. Decomposition kinetics of monoacyl glycerol and fatty acid in subcritical water under temperature-programmed heating conditions. Food Chem. 2006, 94, 341-347. [CrossRef]

26. King, J.W.; Holliday, R.L.; List, G.R. Hydrolysis of soybean oil in a subcritical water flow reactor. Green Chem. 1999, 1, 261-264. [CrossRef]

27. Hossain, M.Z.; Chowdhur, M.B.I.; Jhawar, A.K.; Xu, W.Z.; Biesinger, M.C.; Charpentier, P.A. Continuous Hydrothermal Decarboxylation of Fatty Acids and Their Derivatives into Liquid Hydrocarbons Using Mo/ $\mathrm{Al}_{2} \mathrm{O}_{3}$ Catalyst. J. Am. Chem. Soc. 2018, 3, 7046-7060. [CrossRef] [PubMed]

28. Obeid, R.; Lewis, D.; Smith, N.; Eyk, P.V. The elucidation of reaction kinetics for hydrothermal liquefaction of model macromolecules. Chem. Eng. J. 2019, 370, 637-645. [CrossRef]

29. Kaur, R.; Gera, P.; Jha, M.K.; Bhaskar, T. Reaction parameters effect on hydrothermal liquefaction of castor (Ricinus Communis) residue for energy and valuable hydrocarbons recovery. Renew. Energy 2019. [CrossRef]

30. Chen, Y.; Yang, F.; Wu, L.; Wang, C.; Yang, Z. Co-deoxy-liquefaction of biomass and vegetable oil to hydrocarbon oil: Influence of temperature, residence time, and catalyst. Bioresour. Technol. 2011, 102, 1933-1941. [CrossRef] [PubMed] 
31. Nanda, S.; Rana, R.; Hunter, H.N.; Fang, Z.; Dalai, A.K.; Kozinski, J.A. Hydrothermal catalytic processing of waste cooking oil for hydrogen-rich syngas production. Chem. Eng. Sci. 2019, 195, 935-945. [CrossRef]

32. Sugami, Y.; Minami, E.; Saka, S. Renewable diesel production from rapeseed oil with hydrothermal hydrogenation and subsequent decarboxylation. Fuel 2016, 166, 376-381. [CrossRef]

33. Jin, M.; Choi, M. Hydrothermal deoxygenation of triglycerides over carbon-supported bimetallic PtRe catalysts without an external hydrogen source. Mol. Catal. 2019, 474, 110419. [CrossRef]

34. Yang, C.; Nie, R.; Fu, J.; Hou, Z.; Lu, X. Production of aviation fuel via catalytic hydrothermal decarboxylation of fatty acids in microalgae oil. Bioresour. Technol. 2013, 146, 569-573. [CrossRef] [PubMed]

35. Miao, C.; Marin-Flores, O.; Davidson, S.D.; Li, T.; Dong, T.; Gao, D.; Wang, Y.; Garcia-Pérez, M.; Chen, S. Hydrothermal catalytic deoxygenation of palmitic acid over nickel catalyst. Fuel 2016, 166, 302-308. [CrossRef]

36. Zhang, Z.; Chen, Z.; Gou, X.; Chen, H.; Chen, K.; Lu, X.; Ouyang, P.; Fu, J. Catalytic Decarboxylation and Aromatization of Oleic Acid over Ni/AC without an Added Hydrogen Donor. Ind. Eng. Chem. Res. 2018, 57, 8443-8448. [CrossRef]

37. Edeh, I.; Overton, T.; Bowra, S. Catalytic hydrothermal deoxygenation of fatty acids over palladium on activated carbon catalyst $(\mathrm{Pd} / \mathrm{C})$ for renewable diesel production. Biofuels 2019. [CrossRef]

38. Zhang, J.; Huo, X.; Li, Y.; Strathmann, T.J. Catalytic Hydrothermal Decarboxylation and Cracking of Fatty Acids and Lipids over Ru/C. ACS Sustain. Chem. Eng. 2019, 7, 14400-14410. [CrossRef]

39. Mo, N.; Savage, P.E. Hydrothermal catalytic cracking of fatty acids with HZSM-5. ACS Sustain. Chem. Eng. 2014, 2, 88-94. [CrossRef]

40. Khuwijitjaru, P.; Adachi, S.; Matsuno, R. Solubility of Saturated Fatty Acids in Water at Elevated Temperatures. Biosci. Biotechnol. Biochem. 2002, 66, 1723-1726. [CrossRef] [PubMed]

41. Khuwijitjaru, P.; Fujii, T.; Adachi, S.; Kimura, Y.; Matsuno, R. Kinetics on the hydrolysis of fatty acid esters in subcritical water. Chem. Eng. J. 2004, 99, 1-4. [CrossRef]

42. Khuwijitjaru, P.; Kimura, Y.; Matsuno, R.; Adachi, S. Solubility of oleic and linoleic acids in subcritical water. Food Sci. Technol. Res. 2004, 10, 261-263. [CrossRef]

43. Watanabe, M.; Iida, T.; Inomata, H. Decomposition of a long chain saturated fatty acid with some additives in hot compressed water. Energy Convers. Manag. 2006, 47, 3344-3350. [CrossRef]

44. Robin, T.F.; Ross, A.B.; Lea-Langton, A.; Jones, J. Stability and activity of doped transition metal zeolites in the hydrothermal processing. Front. Energy 2015, 3, 51. [CrossRef]

45. Hossain, M.Z.; Jhawar, A.K.; Chowdhury, M.B.I.; Xu, W.Z.; Charpentier, P.A. Deactivation and regeneration studies of activated carbon during continuous decarboxylation of oleic acid in subcritical water. Fuel 2018, 231, 253-263. [CrossRef]

46. Fu, J.; Lu, X.; Savage, P.E. Hydrothermal decarboxylation and hydrogenation of fatty acids over $\mathrm{Pt} / \mathrm{C}$. ChemSusChem 2011, 4, 481-486. [CrossRef]

47. Yeh, M.T.; Hockstad, R.L.; Linic, S.; Savage, P.E. Hydrothermal decarboxylation of unsaturated fatty acids over PtSnx=C Catalysts. Fuel 2015, 156, 219-224. [CrossRef]

48. Fu, J.; Shi, F.; Thompson, L.T.; Lu, X.; Savage, P.E. Activated carbons for hydrothermal decarboxylation of fatty acids. Catalysis 2011, 1, 227-231. [CrossRef]

49. Miao, C.; Marin-Flores, O.; Dong, T.; Gao, D.; Wang, Y.; Garcia-Perez, M.; Chen, S. Hydrothermal Catalytic Deoxygenation of Fatty Acid and Bio-oil with In Situ $\mathrm{H}_{2}$. ACS Sustain. Chem. Eng. 2018, 6, 4521-4530. [CrossRef]

50. Kim, D.; Vardon, D.R.; Murali, D.; Sharma, B.K.; Strathmann, T.J. Valorization of Waste Lipids through Hydrothermal Catalytic Conversion to Liquid Hydrocarbon Fuels with in Situ Hydrogen Production. ACS Sustain. Chem. Eng. 2016, 4, 1775-1784. [CrossRef]

51. Edeh, I.; Overton, T.; Bowra, S. Renewable diesel production by hydrothermal decarboxylation of fatty acids over platinum on carbon catalyst. Biofuels 2019. [CrossRef]

52. Hossain, M.Z.; Jhawar, A.K.; Chowdhury, M.B.I.; Xu, W.Z.; Wu, W.; Hiscott, D.V.; Charpentier, P.A. Using Subcritical Water for Decarboxylation of Oleic Acid into Fuel Range Hydrocarbons. Energy Fuels 2017, 31, 4013-4023. [CrossRef] 
53. Shin, H.-Y.; Ryu, J.-H.; Park, S.-Y.; Bae, S.-Y. Thermal stability of fatty acids in subcritical water. J. Anal. Appl. Pyrol. 2012, 98, 250-253. [CrossRef]

54. Hollak, S.A.W.; Ariëns, M.A.; de Jong, K.P.; Van Es, D.S. Hydrothermal deoxygenation of triglycerides over $\mathrm{Pd} / \mathrm{C}$ aided by in situ hydrogen production from glycerol reforming. ChemSusChem 2014, 7, 1057-1060. [CrossRef] 